\title{
Boundaries potentiate polycomb response element-mediated silencing
}

\author{
Maksim Erokhin ${ }^{1 *}$, Fedor Gorbenko ${ }^{1,2}$, Dmitry Lomaev ${ }^{3}$, Marina Yu Mazina ${ }^{4}$, Anna Mikhailova ${ }^{1}$, Azat K. Garaev, \\ Aleksander Parshikov ${ }^{6}$, Nadezhda E. Vorobyeva ${ }^{4}$, Pavel Georgiev ${ }^{6}$, Paul Schedl ${ }^{7 *}$ and Darya Chetverina ${ }^{3^{*}}$ (D)
}

\begin{abstract}
Background: Epigenetic memory plays a critical role in the establishment and maintenance of cell identities in multicellular organisms. Polycomb and trithorax group (PcG and TrxG) proteins are responsible for epigenetic memory, and in flies, they are recruited to specialized DNA regulatory elements termed polycomb response elements (PREs). Previous transgene studies have shown that PREs can silence reporter genes outside of their normal context, often by pairing sensitive (PSS) mechanism; however, their silencing activity is non-autonomous and depends upon the surrounding chromatin context. It is not known why PRE activity depends on the local environment or what outside factors can induce silencing.

Results: Using an attP system in Drosophila, we find that the so-called neutral chromatin environments vary substantially in their ability to support the silencing activity of the well-characterized bxdPRE. In refractory chromosomal contexts, factors required for PcG-silencing are unable to gain access to the PRE. Silencing activity can be rescued by linking the bxdPRE to a boundary element (insulator). When placed next to the PRE, the boundaries induce an alteration in chromatin structure enabling factors critical for PcG silencing to gain access to the bxdPRE. When placed at a distance from the bxdPRE, boundaries induce PSS by bringing the bxdPREs on each homolog in close proximity.
\end{abstract}

Conclusion: This proof-of-concept study demonstrates that the repressing activity of PREs can be induced or enhanced by nearby boundary elements.

Keywords: Polycomb, Chromatin silencing, Repression, Bithorax, bxd, Engrailed, Architectural protein, Boundary protein, Insulator, Trithorax

\section{Background}

In many developmental systems, the mechanisms involved in the choice of cell fate are distinct from those deployed for maintaining or remembering cell fate decisions. One classic example of choice is the establishment of parasegment identity in the posterior $2 / 3$ rds of Drosophila embryo by the three bithorax complex (BX-C)

\footnotetext{
* Correspondence: yermaxbio@yandex.ru; pschedl@Princeton.EDU; daria.chetverina@gmail.com

'Group of Chromatin Biology, Institute of Gene Biology, Russian Academy of Sciences, 34/5 Vavilov St., Moscow 119334, Russia

7Department of Molecular Biology Princeton University, Princeton, NJ 08544, USA

${ }^{3}$ Group of Epigenetics, Institute of Gene Biology, Russian Academy of Sciences, 34/5 Vavilov St., Moscow 119334, Russia

Full list of author information is available at the end of the article
}

homeotic genes: Ultrabithorax $(U b x)$, abdominal- $A$ $(a b d-A)$, and Abdominal-B $(A b d-B)$ [1-3]. These genes are controlled by nine parasegment-specific regulatory domains, which are sequentially activated along the anterior-posterior axis by the combined action of gap, pair-rule, and maternal gene products in blastoderm stage embryos. $U b x$ determines segment identity in two parasegments, PS5 and PS6, and its expression in these parasegments is controlled by the $a b x / b x$ and $b x d / p b x$ regulatory domains, respectively. $a b x / b x$ is activated at the blastoderm stage in PS5, while $b x d / p b x$ is silenced. In PS6, both domains are active, but $U b x$ expression is controlled by $b x d / p b x$.

The maternal and early zygotic gene products that initially determine the appropriate activity state of the BX-

(c) The Author(s). 2021 Open Access This article is licensed under a Creative Commons Attribution 4.0 International License, which permits use, sharing, adaptation, distribution and reproduction in any medium or format, as long as you give appropriate credit to the original author(s) and the source, provide a link to the Creative Commons licence, and indicate if changes were made. The images or other third party material in this article are included in the article's Creative Commons licence, unless indicated otherwise in a credit line to the material. If material is not included in the article's Creative Commons licence and your intended use is not permitted by statutory regulation or exceeds the permitted use, you will need to obtain permission directly from the copyright holder. To view a copy of this licence, visit http://creativecommons.org/licenses/by/4.0/ The Creative Commons Public Domain Dedication waiver (http://creativecommons.org/publicdomain/zero/1.0/) applies to the data made available in this article, unless otherwise stated in a credit line to the data. 
C regulatory domains for each parasegment disappear after the onset of gastrulation. Consequently, a different mechanism is required to remember whether the domain is on or off during the rest of development. The memory mechanism is epigenetic. The off or silenced state is remembered by Polycomb group proteins (PcG), while the on or active state is maintained by trithorax group proteins (TrxG) [4-10]. PcG and TrxG proteins not only control the transcriptional activity of the Hox complex genes, but also many other genes implicated in different aspects of development and differentiation. Moreover, disruption of the PcG or TrxG maintenance systems can result in developmental abnormalities and other pathologies [11-16].

In Drosophila, most of the known PcG proteins are components of three complexes: polycomb repressive complexes 1 and 2 (PRC1 and PRC2) and Pho repressive complex (PhoRC). The canonical PRC1 core subunits are sex combs extra (Sce, also known as dRing), posterior sex combs (Psc), polycomb (Pc), and polyhomeotic $(\mathrm{Ph})$ proteins [17-19]. The PRC2 core subcomplex contains enhancer of zeste $(\mathrm{E}(\mathrm{z}))$, extra sex combs (Esc), suppressor of zeste $12(\mathrm{Su}(\mathrm{z}) 12)$, and chromatin assembly factor 1 (Caf1) subunits [20,21]. Finally PhoRC is a DNA-binding complex consisting of Sfmbt [22] and DNA-binding protein pleiohomeotic (Pho) [23]. The TrxG proteins are a more heterogeneous group of proteins which includes the histone H3K4-specific methyltransferase trithorax ( $\operatorname{Trx}$ ), the histone acetyltransferase $\mathrm{CBP}$, and components of chromatin remodeling BAP/ PBAP complexes [5, 7, 9, 24, 25].

The PcG and TrxG proteins are recruited to their regulatory targets by specialized DNA elements called PREs (polycomb response elements) [26-29]. PREs are present in each of the BX-C regulatory domains including the two domains, $a b x / b x$ and $b x d / p b x$, that control Ubx expression [30, 31]. They are also found in the chromatin domains associated with other key developmental transcription factors such as engrailed and evenskipped [32, 33]. The binding of PcG/TrxG proteins to PREs is mediated by sequence-specific DNA-binding proteins, including Pho [23, 34] and Combgap [35].

One characteristic activity of PREs that can be readily assayed is their ability to induce pairing-sensitive silencing (PSS) $[33,36]$. This phenomenon was first observed when the eye colors of flies carrying transgenes with a white reporter and a PRE were compared in hemizygotes and homozygotes. In classical PSS, there is little or no evidence of silencing in hemizygous flies, while strong silencing is evident when the transgene is homozygous. Since PSS is typically observed for transgenes inserted at the same chromosomal site, but not at different sites, the enhancement of repression in homozygotes is thought to be due to trans interactions between the two copies of the PRE, one on each homolog [33, 36]. The effects of pairing have also been observed for PREs in their endogenous context [37].

The activity of PRE elements in these transgene experiments is influenced by the surrounding chromatin environment. Depending on the integration site, PREs can repress and have a neutral or even a positive impact on gene transcription [33, 38-46]. While these findings indicate that PRE activity is modulated by the chromosomal context, it is not clear what features of the immediate neighborhood are important and why. Since PREs do not seem to be functionally autonomous, one idea is that other nearby regulatory elements can impact their activities. In this respect, it is interesting to note that in the $A b d-B$ region of BX-C, the PREs for the $i a b$ $5, i a b-6, i a b-7$, and $i a b-8$ regulatory domains are located in relatively close proximity to the chromatin boundary elements (insulators) that flank these domains [1, 4749]. In BX-C, boundary elements define the centromere proximal ends of the regulatory domain: $M c p$ for $i a b-5$; Fab-6 for $i a b-6$; Fab-7 for $i a b-7$, and Fab-8 for $i a b-8$ [1]. Moreover, at least in the case of Fab-7 and $M c p$, the PRE and boundary are integral parts of the same regulatory element [37, 50-52]. The close linkage between chromatin boundaries and PREs raises the possibility that these architectural elements might facilitate the acquisition of silencing activity by PREs. Consistent with this idea, self-pairing interactions between the $\mathrm{Su}(\mathrm{Hw})$ and the $M c p$ boundaries were shown to facilitate PSS between transgene inserts megabases from each other and even between transgenes inserted on different chromosomes [53-56]. Similar results have been obtained in transgene assays [57].

In the present study, we tested whether a close linkage between boundaries and PREs can impact the acquisition of silencing activity. We show that in chromosomal contexts that are refractory to PRE-induced silencing, the PREs fail to recruit PcG/TrxG proteins. However, both silencing and recruitment of PRE-associated proteins can be triggered by linking the PRE to an artificial boundary element consisting of multimerized binding sites for the $\mathrm{Su}(\mathrm{Hw}), \mathrm{CTCF}$, or Pita polydactyl zinc finger DNA-binding proteins. Two different mechanisms, one that occurs in cis and the other in trans appear to be in play. The first is observed when the boundary is placed in close proximity to the PRE. In this case, silencing is activated in fly hemizygous for the transgene insert and is enhanced when the transgene is homozygous. The induction of silencing activity in hemizygotes is not dependent on the identity of the linked boundary and is observed for all three boundaries. ChIP experiments indicate that the linked boundary facilitates alterations in the local chromatin structure. In the region spanning the PRE, there is a depletion of histone H3 levels and a 
concomitant recruitment of factors required for PRE function. Interestingly, in the region to either side of the boundary, PRE sequences histone $\mathrm{H} 3$ levels are increased. The second mechanism is observed when the boundary element is separated by $1 \mathrm{~kb}$ or more from the PRE. In this case, silencing is not or at most only weakly activated in hemizygotes. However, silencing activity is induced in homozygous flies. In this case, the mechanism is dependent upon boundary:boundary pairing interactions as it is not observed when the PREs are linked to heterologous instead of homologous boundaries.

\section{Results}

\section{bxdPRE silencing activity depends on the chromosomal context}

In previous studies, PREs were found to repress expression of reporter genes in only about half of the transgene insertion sites [38-41, 58,59]. To better understand the context-dependent factors that impact PRE activity, we used the ФC31 site-specific integration system [60] to generate independent Drosophila transgenic lines. For this purpose, we selected five attP sites that had previously been shown to provide a context in which the expression of a white reporter is not subject to obvious repression or activation by the surrounding chromatin neighborhood (Additional file 1: Table S1). Three attP sites are on the 2nd chromosome (22A, 51C, and 58A), while two are on the 3rd chromosome (68E and 96E). As a PRE, we selected a well-characterized 656-bp $b x d$ PRE element from the $U b x$ regulatory region $[30,31$, 61, 62] (bxd construct, Fig. 1a). To evaluate the silencing activity of the $b x d$ PRE as a reporter, we used a white gene with its eye tissue-specific enhancer (E). The bxdPRE was flanked by $\sim 1 \mathrm{~kb}$ "neutral" spacers derived from coding regions of the eGFP and RFP genes and by terminators of transcription (SV40 terminator upstream and yellow gene terminator downstream) to reduce the influence of potential transcription from surrounding genomic sequences. To better assess the effects of the PRE, we also inserted a control construct at each site, which has all of these components except for bxdPRE (E-w construct, Fig. 1a). The transgene constructs were inserted in $w^{-}$attP lines lacking a functional white gene. The silencing activity of the $b x d$ PRE was assessed by the reduction in eye pigmentation as pigmentation is known to be directly correlated with the level of white gene transcription [62, 63].

Shown in Fig. 1b, c are the eye color phenotypes of hemizygous and homozygous flies for each of the five insertion sites. In the five lines carrying the E-w control transgene, there is no evidence of repression in either hemizygotes or homozygotes (Fig. 1b). In contrast, different degrees of repression are observed in 4 of the 5 lines with the bxd transgene (Fig. 1c). Line $22 \mathrm{~A}$ is a classic example of PSS. It shows little or no evidence of silencing as a hemizygote, while as a homozygote there is a strong and almost uniform reduction in pigmentation. Though PSS is observed for line 58A, it differs from line $22 \mathrm{~A}$ in that only a small sector of the eye shows a significant loss of pigmentation as a homozygote. Unlike $22 \mathrm{~A}$ and $58 \mathrm{~A}$, weak silencing is observed in line $51 \mathrm{C}$ as a hemizygote. However, PSS is also evident as silencing is clearly enhanced when the flies are homozygous for the insert. For line 68E, eye pigmentation is greatly reduced in both hemizygous and homozygous flies. Finally, the $b x d \mathrm{PRE}$ is unable to induce silencing at $96 \mathrm{E}$ insertion site, suggesting that this chromatin environment renders the PRE inactive. In all cases, flies within a given line have similar eye pigmentation phenotypes. Since PSS is thought to be dependent upon homolog pairing, the different properties of the five insertion sites could be due to differences in the strength of local homolog pairing. To investigate this possibility, we took advantage of a recent genome-wide study that measured interaction frequencies between homologs at the embryo stage [64]. However, analysis of the available $\mathrm{Hi}-\mathrm{C}$ data did not show any significant correlations (Additional file 2).

Silencing is expected to be accompanied by the association of PcG proteins with the $b x d$ PRE. To confirm that this is the case, we isolated chromatin from adult heads of homozygous bxdPRE transgene flies and performed chromatin immunoprecipitation (X-ChIP) with antibodies against $\mathrm{Ph}$, which is a core component of the PRC1 complex (Fig. 1d). To compare Ph association in different lines, we calculated the extent of enrichment relative to an internal positive control. For this purpose, we used primers to a sequence immediately adjacent to the endogenous bxdPRE (hereafter referred to as $b x d$ PRE-Genome) that is known to be enriched in PcG/ TrxG proteins. Figure 1c shows that $\mathrm{Ph}$ is associated with the transgenic $b x d$ PRE in the four lines that show silencing of the white gene. Moreover, the extent of association correlates well with the level of repression observed in each line. Consistent with the lack of silencing of white in the 96E insertion, $\mathrm{Ph}$ is not found to be associated with its $b x d \mathrm{PRE}$ sequence.

\section{Multimerized sites for $\mathrm{Su}(\mathrm{Hw})$ boundary induce bxdPRE silencing at $96 \mathrm{E}$}

PREs are often located near other transcriptional regulatory elements. As noted above, the PREs in the four $A b d-B$ regulatory domains are positioned close to the boundary elements for each domain. Another example is one of the PREs for the even-skipped (eve) gene that is located next to the distal boundary of the eve locus homie [32]. These observations led us to wonder 


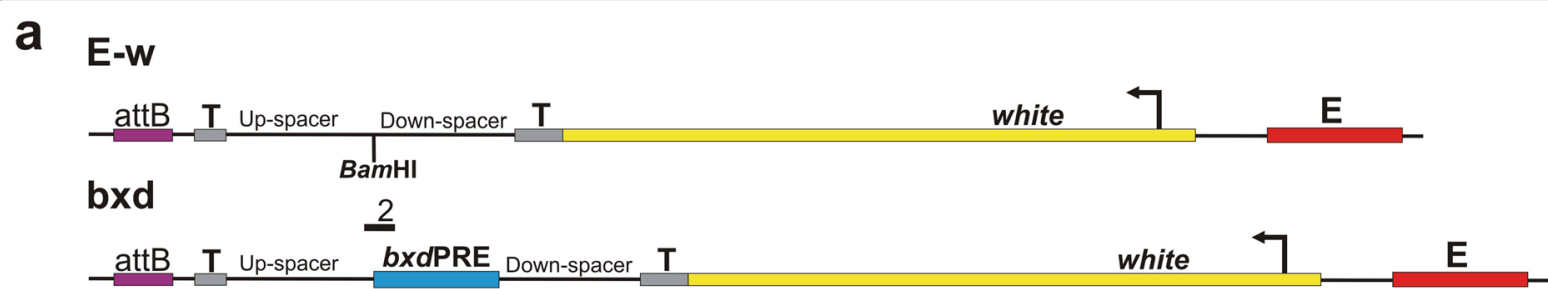

\section{Su-bxd}

_attB_T Up-spacer 4xSu bxdPRE ${ }_{\text {Down-spacer }} \mathrm{T} \quad$ white 7 E

\section{Su}

attB_T Up-spacer 4xSu Down-spacer $T$ white 7 -

b

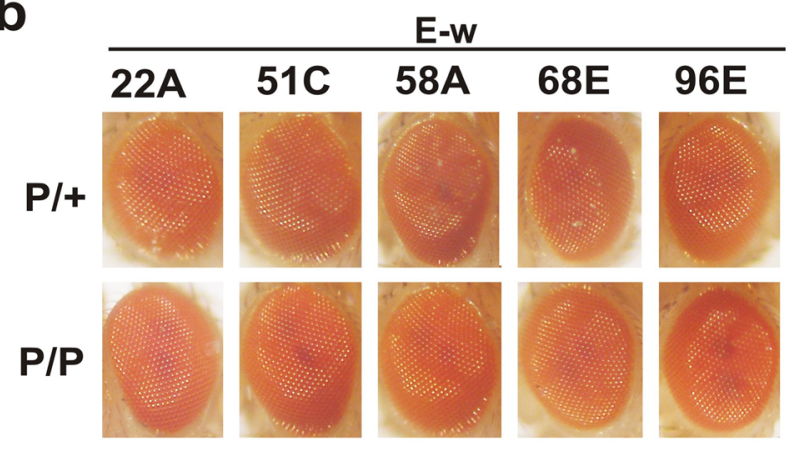

d

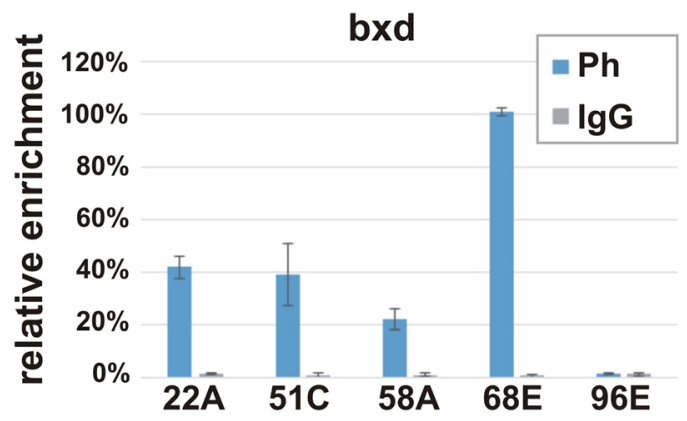

C

bxd

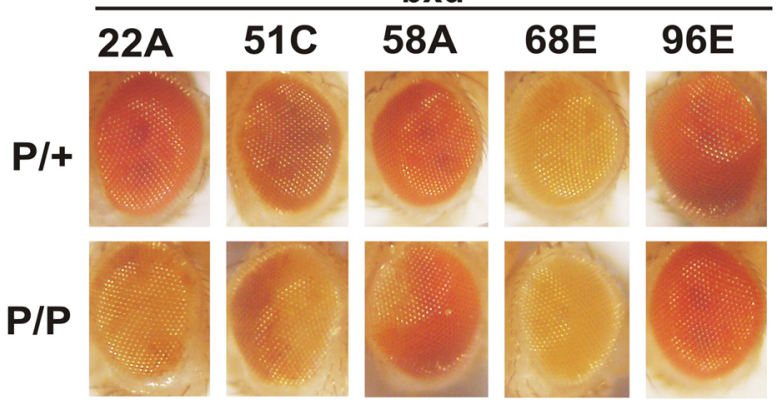

e

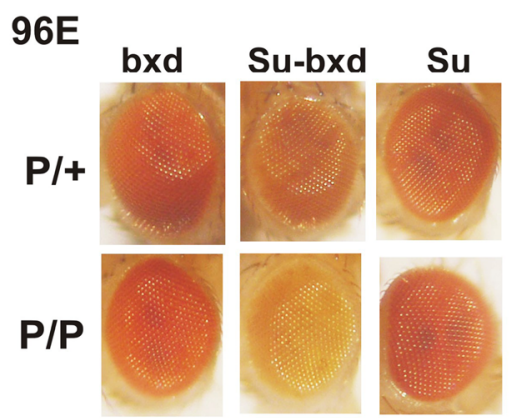

Fig. $1 \mathrm{Su}(\mathrm{Hw})$ binding sites induce bxdPRE silencing activity. a Map of transgenes. Labels: "attB" - attB site required for transgene integration into the attP insertion site; "bxdPRE" - bxdPRE silencing element; "T," terminators of transcription; white -marker gene; "E" - enhancer of the white gene, " $4 \times \mathrm{Su}^{\mathrm{u}}$ - four binding sites for $\mathrm{Su}(\mathrm{Hw})$ protein. $\mathbf{b}$ The eye phenotypes of flies that have the control "E-W" transgene integrated into the different attP sites: 22A (Bloomington Drosophila Stock Center (BDSC) \#24481), 51C (BDSC \#24482), 58A (BDSC \#24484), 68E (BDSC \#24485), 96E (BDSC \#24487). P/+, hemizygous; P/P, homozygous adult flies. c The eye phenotypes of flies that have the "bxd" transgene integrated into the different attP sites: 22A, 51C, 58A, 68E, and 96E. d Ph enrichment at bxdPRE in "bxd" transgenes integrated into the different attP insertion sites. Diagrams summarize the results of X-ChIP with Ph antibody or with IgG from a non-immunized animal as a negative control. X-ChIP was analyzed by realtime PCR with primers specific to transgene bxdPRE - the region indicated by underlined number 2 above the "bxd" transgene map. The X-ChIP experiments were performed with chromatin isolated from the heads of homozygous adult flies. The ordinate shows the percentage of target sequences in the immunoprecipitated material relative to the input DNA and normalized to the positive control—a sequence adjacent to the endogenous bxdPRE in BX-C (bxdPRE-Genome). The line with bxd transgene is designated by its attP insertion site and is indicated on the abscissa. Vertical lines indicate SDs. e The eye phenotypes of flies with the "bxd," "Su-bxd," or "Su" transgenes at the 96E attP site

whether boundary elements might be able to augment the silencing activities of PREs.

To explore this possibility, we selected the $96 \mathrm{E}$ attP since the $b x d \mathrm{PRE}$ is unable to silence white at this insertion site. As the test boundary, we used an artificial element consisting of multimerized binding sites for the polydactyl zinc finger protein $\mathrm{Su}(\mathrm{Hw})$ rather than an endogenous boundary. Endogenous boundaries contain binding sites for many different proteins, and some are known to be required for PRE activity. For example, the 
GAF protein is implicated not only in insulation but also in PcG-dependent silencing [65].

$\mathrm{The} \mathrm{Su}(\mathrm{Hw})$ protein is responsible for the boundary activity of the insulator element associated with the gypsy transposon [66, 67]. The gypsy transposon has 12 binding sites for the $\mathrm{Su}(\mathrm{Hw})$ protein $[68,69]$; however, previous studies have shown that a multimer consisting of only four copies of the third $\mathrm{Su}(\mathrm{Hw})$ binding site from the gypsy insulator is sufficient for boundary activity in transgene reporter assays [70] and in the context of BX$\mathrm{C}$ [71]. This $4 \mathrm{xSu}(\mathrm{Hw})$ multimer was placed on the distal side of the $b x d$ PRE (Fig. 1a: Su-bxd construct) so that the PRE is between it and the white gene. In this position, the $4 \mathrm{xSu}(\mathrm{Hw})$ multimer would not be able to insulate white from PRE-dependent silencing [54, 57, 72]. To assess the effects of the multimer alone, we inserted a control transgene containing $4 \mathrm{xSu}(\mathrm{Hw})$ but not the PRE (Fig. 1a: Su construct). Figure 1e shows that combining $4 \mathrm{xSu}(\mathrm{Hw})$ with the $b x d \mathrm{PRE}$ has a dramatic effect on white expression. Silencing of white is evident in hemizygotes, while strong PSS is observed when the transgene is homozygous. In contrast, the $4 \mathrm{xSu}(\mathrm{Hw})$ multimer alone has no effect on eye pigmentation either as a hemizygote or a homozygote. Thus, the presence of the $4 \mathrm{xSu}(\mathrm{Hw})$ multimer can induce the establishment of silencing by the $b x d$ PRE in a chromosomal location that is not conducive to PcG-dependent silencing.

\section{$\mathrm{Su}(\mathrm{Hw})$ binding facilitates recruitment of PcG/TrxG and PRE DNA-binding proteins to the bxdPRE at 96E}

As shown above, $\mathrm{Ph}$ is recruited to $b x d \mathrm{PRE}$ insertions that are able to repress white expression but is not found associated with the $b x d \mathrm{PRE}$ at 96E. If the addition of the $4 \mathrm{xSu}(\mathrm{Hw})$ multimer induces PcG-dependent repression, it should also facilitate the recruitment of $\mathrm{Ph}$ to the $96 \mathrm{E}$ bxdPRE. To test this prediction, we used ChIP to examine $\mathrm{Ph}$ association at 5 sites in the Su-bxd and bxd transgenes: (1) the distal end of the spacer sequence upstream of $b x d \mathrm{PRE}$, (2) $b x d \mathrm{PRE}$, (3) the distal end of the spacer sequence downstream of $b x d \mathrm{PRE}$, (4) the white transcription unit, and (5) the white promoter (Fig. 2a). As a negative control, we used the Ras64B coding region, while the bxdPRE-Genome region was used as a positive internal control.

As would be predicted from the activation of silencing, there is a substantial increase in $\mathrm{Ph}$ association with the $b x d \mathrm{PRE}$ in the Su-bxd transgene as compared to the bxd transgene (Fig. 2b). While $\mathrm{Ph}$ is enriched at the $b x d \mathrm{PRE}$, its association with the four other sites in the Su-bxd transgene is essentially the same as in the bxd transgene

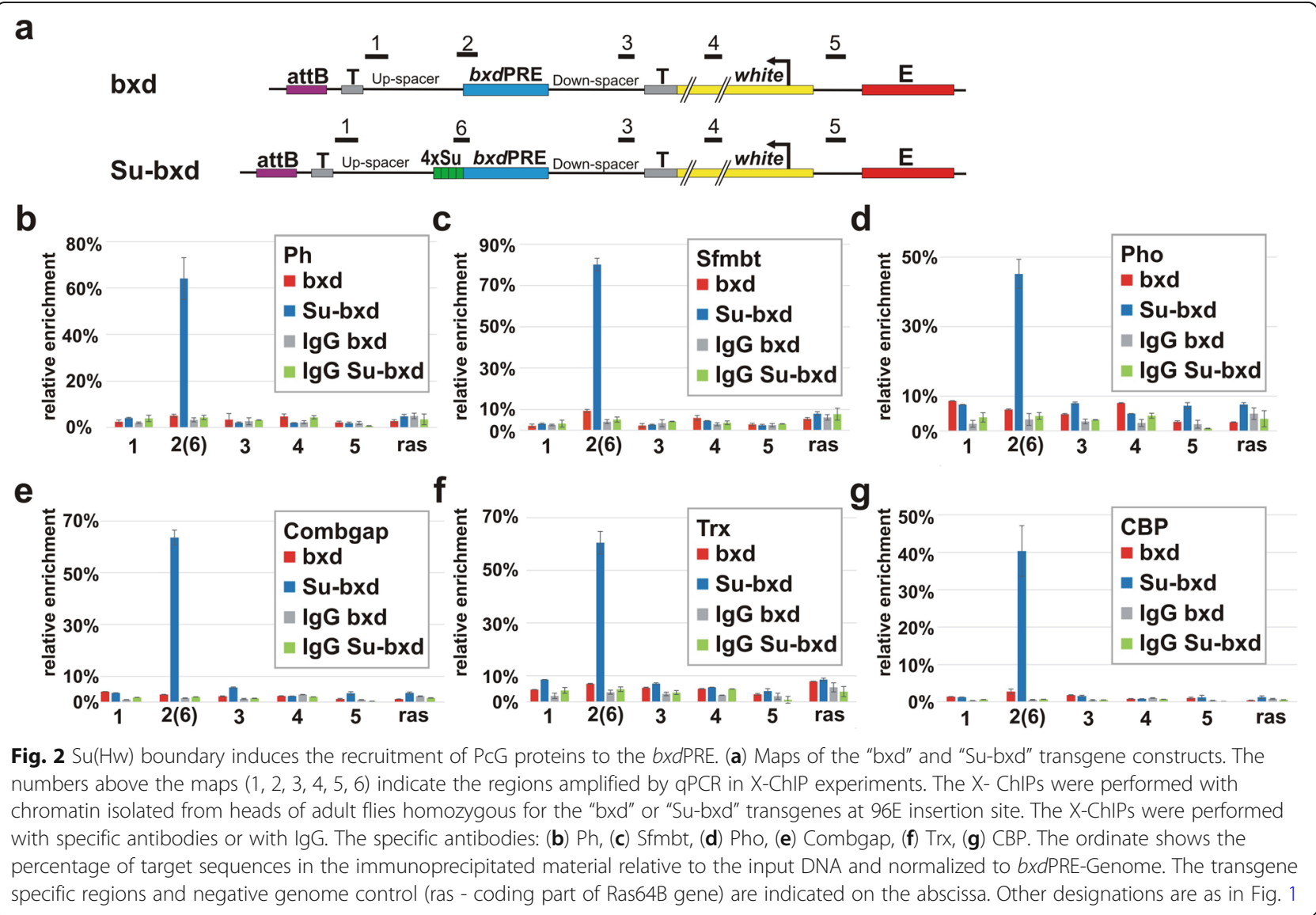


or the negative Ras64B control. This result is consistent with previous ChIP experiments in which we found that $\mathrm{Ph}$ (as well as several other PcG proteins: see below) associates with the $b x d$ PRE element in the transgene construct, but not with other sequences even though white expression is silenced [62]. Like silencing, the recruitment of Ph requires a combination of the $b x d \mathrm{PRE}$ and the $4 \mathrm{xSu}(\mathrm{Hw})$ multimer as $\mathrm{Ph}$ is not associated with the control transgene carrying only the $4 \mathrm{xSu}(\mathrm{Hw})$ multimer (Additional file 1: Figure S1b). Consistent with the idea that the presence of $\mathrm{Su}(\mathrm{Hw})$ protein bound to its target sites is responsible for the acquisition of silencing activity and the recruitment of $\mathrm{Ph}$, we find that $\mathrm{Su}(\mathrm{Hw})$ associates with the $4 \mathrm{x}$ multimer not only in the Su transgene but also the Su-bxd transgene (Additional file 1: Figure S1c).

Biochemical and genetic studies have shown that, like other PREs, the silencing activity of the $b x d$ PRE depends upon several DNA-binding proteins that help recruit the PRC1 and PRC2 complexes. Thus, one explanation for the inability of the $b x d \mathrm{PRE}$ element alone to silence white at 96E is that these DNA-binding proteins are unable to associate with the $b x d$ PRE. In this model, these proteins would be able to access their recognition sequences in the PRE when the $4 \mathrm{xSu}(\mathrm{Hw})$ multimer is included in the transgene, but not when it is absent. The DNA-binding proteins known or thought to be important for $b x d$ PRE silencing include Pho, which binds PREs together with its partner Sfmbt (the PhoRC complex) as well as the Combgap DNA-binding protein. An alternative model is that the $b x d \mathrm{PRE}$ at $96 \mathrm{E}$ is unable to silence because it is occupied by TrxG proteins and these factors block association of $\mathrm{Ph}$ and other PcG proteins and/ or their function. In this case, the presence of the $4 \mathrm{xSu}(\mathrm{Hw})$ multimer could shift the balance to favor of the recruitment of PcG complexes.

To test these two models, we used antibodies against Pho, Sfmbt, Combgap, and two TrxG proteins, Trx and CBP, for ChIP experiments. In the bxd transgene, we observe only background levels of Pho, Sfmbt, and Combgap in ChIPs for the PRE and other sequences in the transgene (Fig. 2c-e). In contrast, all three of these proteins are detected at the bxdPRE in the Su-bxd transgene. These results are consistent with the predictions of the first model. We infer from these finding that the presence of the $4 \mathrm{xSu}(\mathrm{Hw})$ multimer induces the association of key DNA-binding proteins with the $b x d$ PRE.

The second model predicts that TrxG proteins will be associated with the transgene containing the $b x d \mathrm{PRE}$ alone, but will be displaced by PcG proteins when the $4 \mathrm{xSu}(\mathrm{Hw})$ multimer is present. However, like the PcG proteins, the Trx and CBP are recruited to the $b x d \mathrm{PRE}$ only when the $4 \mathrm{xSu}(\mathrm{Hw})$ multimer is present (Fig. 2f, g). Thus, the boundary induces the association of PRE
DNA-binding proteins as well as both PcG and TrxG factors to the $b x d$ PRE. It remains to be determined whether this is actual co-occupancy or whether it reflects instead a heterogeneity in the population such that some PREs are occupied by PcG proteins while others are occupied by TrxG proteins.

\section{The $\mathrm{Su}(\mathrm{Hw})$ multimer augments bxdPRE silencing activity at different chromosomal sites}

Genome-wide ChIPs indicate there is a minor $\mathrm{Su}(\mathrm{Hw})$ peak that overlaps the attP site at 96E, while there are two larger peaks on either side of the attP $\sim 5 \mathrm{~kb}$ and $\sim 10 \mathrm{~kb}$ away (Additional file 3, data from $[73,74])$. This raises the possibility that the $4 \mathrm{xSu}(\mathrm{Hw})$ multimer is able to rescue the silencing activity of the $b x d \mathrm{PRE}$ at this particular attP site only because of the endogenous $\mathrm{Su}(\mathrm{Hw})$ protein. For this reason, we asked whether the $4 \mathrm{xSu}(\mathrm{Hw})$ multimer is able to augment $b x d \mathrm{PRE}$ silencing at the four other attP sites which do not have peaks for $\mathrm{Su}(\mathrm{Hw})$ nearby (Additional file 3). To control for the effects of the $\mathrm{Su}(\mathrm{Hw})$ binding sites on transcriptional activity, the $\mathrm{Su}$ transgene was inserted at these other attP sites as well. Shown in Fig. 3 is a comparison of the silencing activity of the $b x d \mathrm{PRE}$ with and without the $4 \mathrm{xSu}(\mathrm{Hw})$ multimer (Fig. 3a,b) and $4 \mathrm{xSu}(\mathrm{Hw})$ multimer alone (Fig. $3 \mathrm{c}$ ). For inserts at 22A, 51C, and 58A, silencing of white in hemizygotes is enhanced when $4 \mathrm{xSu}(\mathrm{Hw})$ is included next to $b x d \mathrm{PRE}$ in the transgene (Fig. 3b). While there is no obvious effect on the silencing of inserts at 68E (Fig. $3 \mathrm{~b})$, the $b x d \mathrm{PRE}$ already strongly silences on its own as either a hemizygote or homozygote (Fig. 3a). In homozygotes, the $22 \mathrm{~A}$ insertion containing $4 \mathrm{xSu}(\mathrm{Hw})$ and $b x d$ PRE is lethal, while the PSS observed for the 58A insert is clearly stronger when the $4 \mathrm{xSu}(\mathrm{Hw})$ multimer is present (Fig. 3b). Although there is no obvious difference between hemizygotes and homozygotes for the Su-bxd transgene inserted at $51 \mathrm{C}$, silencing is substantially greater when the $4 \mathrm{xSu}(\mathrm{Hw})$ multimer is present (Fig. $3 \mathrm{~b})$. For the control construct, the $\mathrm{Su}(\mathrm{Hw})$ multimer alone, there is no evidence for silencing in any of these lines either in hemi- or homozygotes (Fig. 3c). Taken together, these findings indicate that the $4 \mathrm{xSu}(\mathrm{Hw})$ multimer can augment the silencing activity of the $b x d \mathrm{PRE}$ in different chromosomal environments.

\section{Binding sites for architectural proteins CTCF and Pita can induce bxdPRE silencing}

Next, we wondered whether induction of PRE repressing activity is unique to $\mathrm{Su}(\mathrm{Hw})$ or whether other polydactyl zinc finger proteins that have chromosome architectural functions are able to induce PRE silencing. To test this, we linked the $b x d \mathrm{PRE}$ to either a Drosophila $4 \mathrm{xCTCF}$ multimer or a $5 x$ Pita multimer. Like $4 x \mathrm{Su}(\mathrm{Hw})$, both of these multimers have insulating activity in BX-C 


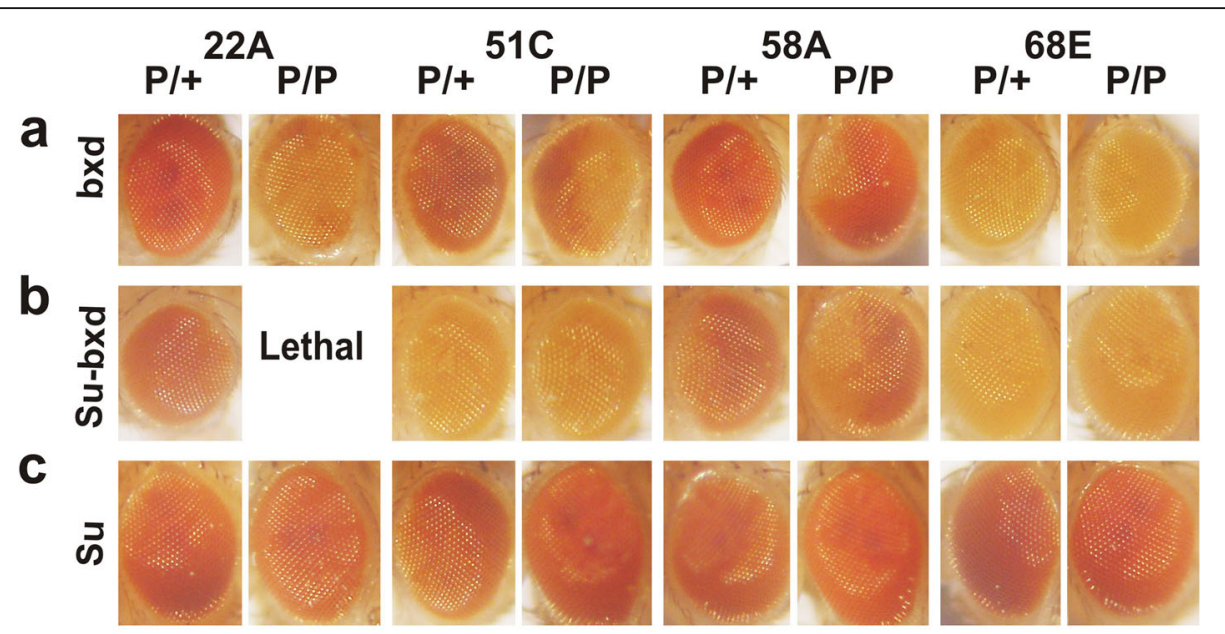

Fig. $3 \mathrm{Su}(\mathrm{Hw})$ multimer can stimulate bxdPRE silencing activity at different insertion sites. 22A, 51C, 58A and 68E - designates the chromosome position of attP insertion sites. Phenotypes of eyes of adult flies with (a) bxd, (b) Su-bxd, and (c) Su transgenes in hemizygotes (P/+) and homozygotes (P/P)

boundary replacement experiments [71, 75-77]. Figure 4 shows that combining either $4 x \mathrm{xTCF}$ or $5 \mathrm{xPita}$ with the $b x d$ PRE induces silencing activity in hemizygotes and PSS in homozygotes. Control experiments show that white expression is not affected when the multimers are included in the transgene alone. Thus, multimerized sites for three different chromosomal architectural proteins can induce the silencing activity of the $b x d \mathrm{PRE}$.

\section{$\mathrm{Su}(\mathrm{Hw})$ architectural protein induces enPRE silencing activity}

We also used the same strategy to test the silencing activity of another well-defined PRE, the 181 bp enPRE (PSE2) from the engrailed locus, in different chromosomal environments. In previous P-element transgene experiments, this element was shown to repress white expression as a hemizygote and/or homozygote and maintain the parasegmental expression pattern of a $U b x$ reporter [33, 38, 46, 59, 78-82]. Surprisingly, however, repression of white by the enPRE in hemizygote flies is weak or nonexistent at all five attP insertion sites and there is no evidence of PSS when the inserts are homozygous (en construct, Fig. 5a, b) Moreover, Ph binding is not detected at the enPRE in homozygous insertions of this construct (Fig. 5c).

Since the lack of silencing was unexpected, we tested whether silencing activity could be induced by linking the $4 \mathrm{xSu}(\mathrm{Hw})$ multimer to the enPRE (Su-en construct, Fig. 5a). For this purpose, we chose the $68 \mathrm{E}$ attP integration site as it was most permissive for $b x d \mathrm{PRE}$ silencing. Figure $5 \mathrm{~b}$ shows that the eye pigmentation of hemizygous $\mathrm{Su}$-en flies is similar to that observed for en flies; however, silencing is observed in flies homozygous for the $68 \mathrm{E}$ insert. This is opposite of that observed for the en transgene at $68 \mathrm{E}$ where the eye color in homozygotes becomes darker not lighter. ChIP experiments provide further evidence that $4 \mathrm{xSu}(\mathrm{Hw})$ is able to activate PcGdependent silencing. While $\mathrm{Ph}$ and Sfmbt are not associated with the enPRE in the en transgene, both are recruited to the enPRE when it is linked to $4 \mathrm{xSu}(\mathrm{Hw})$ (Fig. 5c).

\section{Increasing the distance between the bxdPRE and the} boundary element disrupts silencing in hemizygotes How do the architectural proteins help establish PRE activity? Two different mechanisms could be in play. The architectural proteins could facilitate the establishment of PcG silencing by locally displacing nucleosomes and/ or by recruiting chromatin remodeling complexes so that key DNA-binding factors and PcG complexes are able to assemble on the PRE. Alternatively, the architectural proteins could enhance PRE activity by helping target the transgene from an active chromosomal compartment to a PcG-silenced chromosomal compartment [83]. Since the effects of nucleosome displacement and chromatin remodeling are expected to be limited to closely linked sequences, the former model predicts that the impact of architectural proteins on the establishment of PcG silencing will decrease as the distance between the multimers and the $b x d \mathrm{PRE}$ is increased. In the latter model, relatively small changes in distance $(<10 \mathrm{~kb})$ should have little or no effect on the ability of the boundary to target the transgene to a PcG-silenced compartment.

To test these two models, we increased the distance between the $4 \times \mathrm{Su}(\mathrm{Hw})$ or $4 \mathrm{xCTCF}$ multimers and the $b x d$ PRE by $1 \mathrm{~kb}$ and $3 \mathrm{~kb}$ (Fig. 6a). For the distance of $1 \mathrm{~kb}$, we inserted each multimer upstream of the left eGFP coding sequence spacer (the Su-1kb-bxd and CTCF-1kb-bxd constructs). To adjust the 


\section{E}

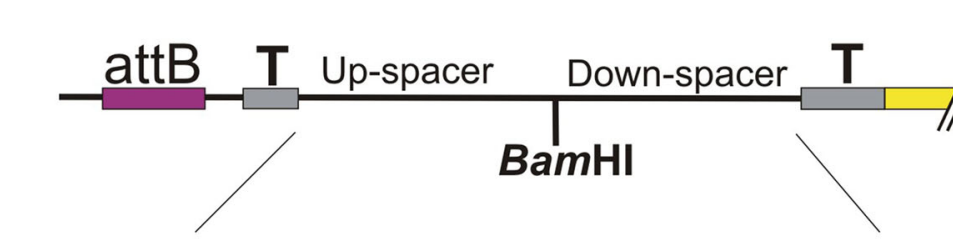

bxd

T Up-spacer bxdPRE Down-spacer $T$

\section{CTCF-bxd}

\section{TUp-spacer 4xCTCF bxdPRE Down-spacer $T$}

\section{CTCF}

\section{T_Up-spacer 4xCTCF Down-spacer, $T$}

Pita-bxd

\section{T_up-spacer 5xPita bxdPRE ${ }_{\text {Down-spacer }} \mathbf{T}$}

\section{Pita}

$$
\text { T Up-spacer 5xPita Down-spacer } \mathbf{T}
$$
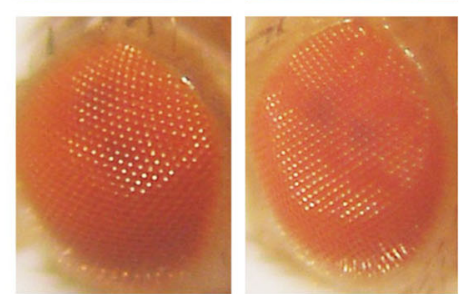

Fig. 4 CTCF and Pita multimers induce bxdPRE silencing activity. Transgenes were integrated into 96E attP insertion site. Designations: "4xCTCF"-four binding sites for CTCF protein; "5xPita" - five binding sites for Pita protein. Other designations are as on Fig. 1

distance between the multimers and the PRE to $3 \mathrm{~kb}$, we introduced an additional $2 \mathrm{~kb}$ spacer derived from the Escherichia coli LacZ coding sequence (the Su3kb-bxd and CTCF-3kb-bxd constructs). A 1-kb distance would be sufficient for approximately five nucleosomes, while $3 \mathrm{~kb}$ would correspond to about fifteen nucleosomes. All of the constructs were then introduced into the $96 \mathrm{E}$ attP site. The results of this analysis are shown in Fig. 6 . In hemizygotes $(\mathrm{P} /+)$ increasing the distance between the multimer and the $b x d$ PRE adversely impacts silencing activity. For the $4 \mathrm{xSu}(\mathrm{Hw})$ multimer, a distance of $1 \mathrm{~kb}$ is sufficient to 


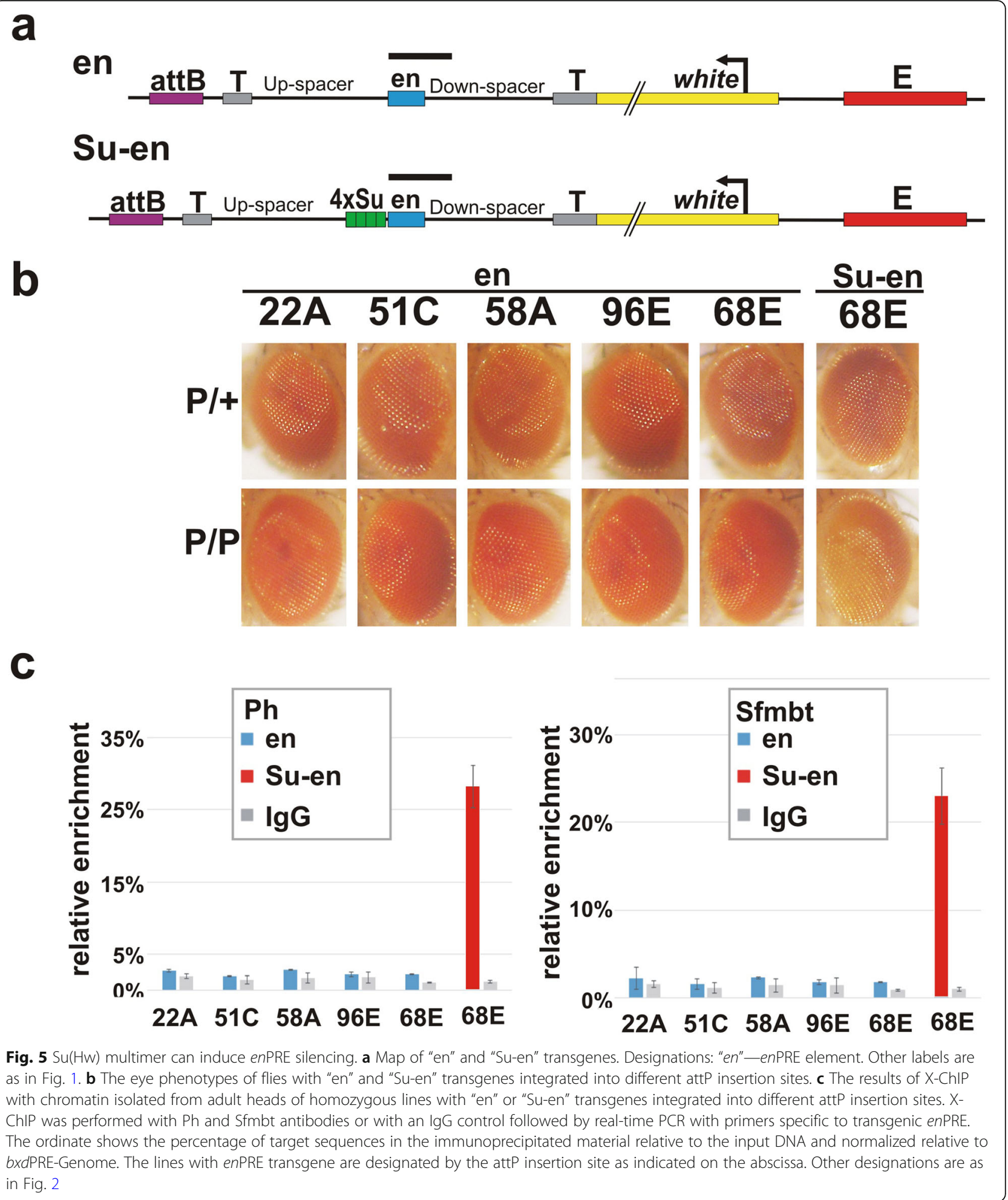

substantially reduce silencing (compare with $b x d \mathrm{PRE}$ alone). In the case of the $4 \mathrm{xCTCF}$ multimer, the disruption of silencing is greater when it is located $3 \mathrm{~kb}$ away from the $b x d$ PRE than it is at a $1-\mathrm{kb}$ distance; however, even at $1 \mathrm{~kb}$, silencing is reduced compared to the control CTCF-bxd construct. These findings argue in favor of the first model, namely that the $4 \mathrm{xSu}(\mathrm{Hw})$ and $4 \mathrm{xCTCF}$ multimers act in cis to facilitate the assembly of silencing complexes on the PRE (Fig. 6c). 


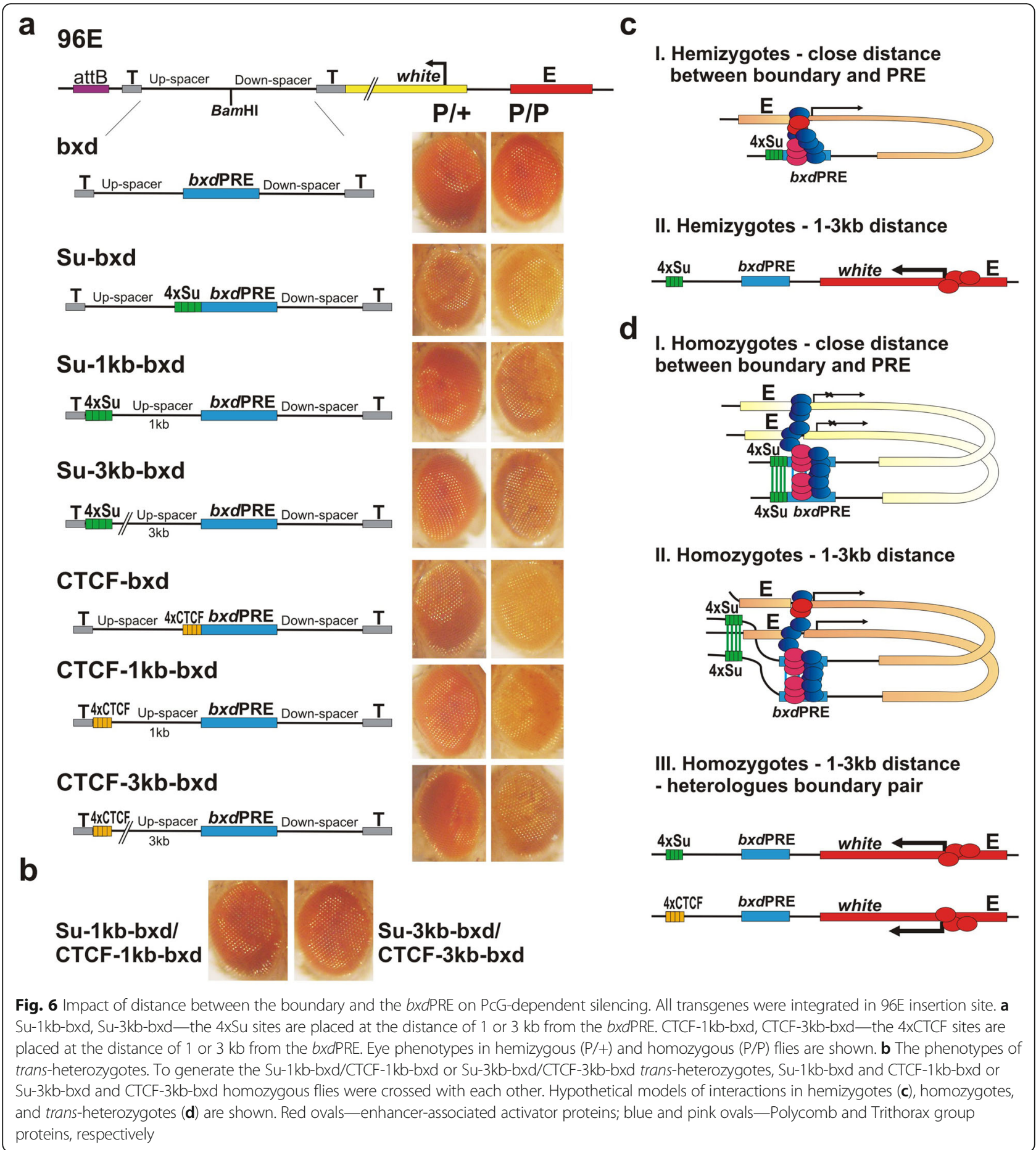

Boundaries located at a distance from the bxdPRE can induce PSS

While silencing activity in hemizygotes is significantly compromised when the multimers are moved away from the $b x d$ PRE, this is not true for PSS. As shown in Fig. 6 $(\mathrm{P} / \mathrm{P})$, the $b x d \mathrm{PRE}$ represses white expression even when the boundary multimers are located $3 \mathrm{~kb}$ away. A plausible explanation for this result is that pairing of the
$4 \mathrm{xSu}(\mathrm{Hw})$ or $4 \mathrm{xCTCF}$ multimers in trans would tend to stabilize pairing interactions between the PREs on each homolog, and this interaction facilitates the PSSdependent assembly of functional silencing complexes.

Boundary pairing in Drosophila depends upon specific interactions between proteins associated with each element [56, 84-86]. A classic example of specificity comes from the boundary bypass assay. In this assay, an 
upstream regulatory element (enhancer or silencer) is separated from a reporter gene by a spacer DNA that is flanked by two boundary elements (endogenous or artificial). If the boundaries flanking the spacer DNA can pair with other, the upstream regulatory element is brought into close proximity with the reporter and can either activate (enhancer) or repress (silencer) its expression [48, $55,57,87,88]$. This is what is found when the spacer DNA is flanked by either $\mathrm{Su}(\mathrm{Hw})$ or CTCF multimers [81]. On other hand, bypass is not observed when the spacer DNA is flanked by a heterologous combination of $\mathrm{Su}(\mathrm{Hw})$ multimers and CTCF multimers [89]. Thus, if boundary-boundary interactions between homologs are required to induce PRE repression, then PSS should not be observed in the two sets of mixed pairs: Su-1kb-bxd trans to CTCF-1kb-bxd or Su-3kb-bxd trans to CTCF$3 \mathrm{~kb}-\mathrm{bxd}$. Figure $6 \mathrm{~b}$ shows that this prediction is correct: silencing depends on boundary pairing in trans and is not observed in heterologous combinations. A possible model is shown in Fig. 6d.

\section{Binding sites of architectural proteins leads to local decrease of histone $\mathrm{H} 3$ enrichment}

The finding that the boundary element must be closely linked to the $b x d$ PRE for silencing in hemizygotes and enhanced PSS in homozygotes suggests that the boundary has a local effect on chromatin structure that enables PcG factors to gain access to the PRE and assemble functional silencing complexes. If this suggestion is correct, then the chromatin organization of the $b x d \mathrm{PRE}$ should be altered when it is closely linked to a boundary element. To test this prediction, we analyzed histone $\mathrm{H} 3$ association with six unique sequences (1n-6n) located at different distances upstream and downstream of the BamH1 site used to insert test DNAs (Fig. 7a). The distance between the midpoints of the $3 \mathrm{n}$ and $4 \mathrm{n}$ sequences and the BamH1 site are $75 \mathrm{bp}$ and $83 \mathrm{bp}$, respectively. The midpoints of $2 \mathrm{n}$ and $5 \mathrm{n}$ are $187 \mathrm{bp}$ and $233 \mathrm{bp}$ from the BamH1 site, respectively, while those for $1 \mathrm{n}$ and $3 \mathrm{n}$ are 301 and $365 \mathrm{bp}$.

In the control E-w transgene, histone $\mathrm{H} 3$ association as measure by ChIP is nearly the same in all regions tested $(1 n-6 n)$ and is equivalent to that observed for the control genomic sequence in the coding region of the Ras64B gene (ras) (Fig. 7b). The inclusion of the $b x d$ PRE in the transgene (bxd) has no apparent effect on histone $\mathrm{H} 3$ occupancy and the profile across the six sequences is similar to that of the E-w control. A different result is obtained for $\mathrm{Su}, \mathrm{CTCF}$, or Pita transgenes containing the multimerized binding sites for the boundary proteins. In all three cases, there is a reduction in histone $\mathrm{H} 3$ occupancy in the sequences located immediately next to the multimers (Fig. 7b). This finding indicates that the

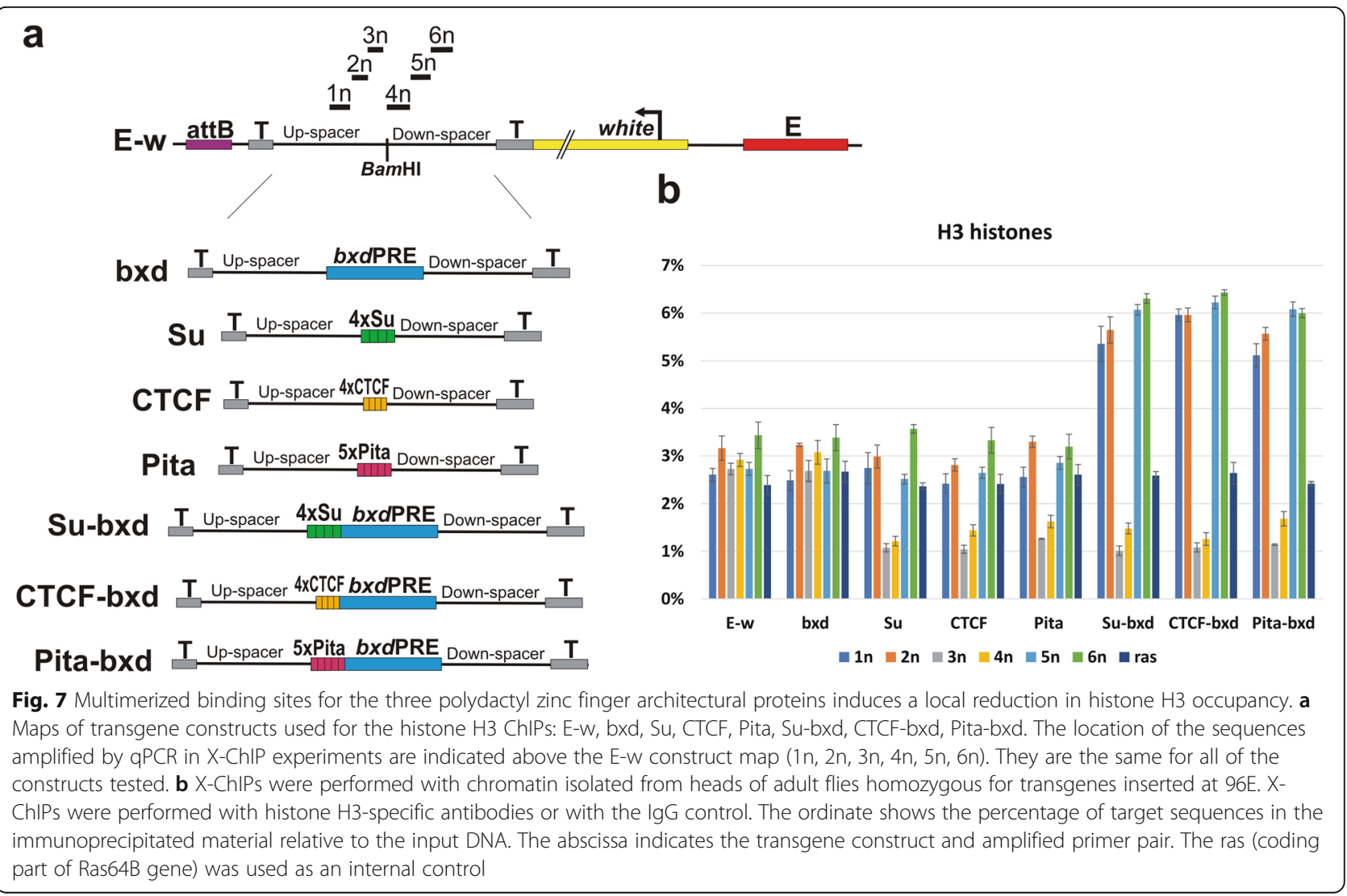


multimerized sites for these three chromosomal architectural proteins generate a region that is depleted in nucleosomes. This effect is local and does not extend to sequences located more distant (1n, 2n, 5n, and 6n) from the multimerized sites.

We next examined the Su-bxd, CTCF-bxd, and Pitabxd transgenes (Fig. 7b). As was observed for the transgenes containing only the multimerized binding sites, histone association with the two sequences, $3 \mathrm{n}$ and $4 \mathrm{n}$, that immediately flank the multimer-bxdPRE combination is reduced. In each case, the reduction is approximately the same as that observed for the corresponding multimer alone. Importantly, this is true for $4 \mathrm{n}$, which is separated from the multimers by the $650 \mathrm{bp} b x d$ PRE. These results provide strong support for the idea that closely linked boundary elements can induce alterations in the association of nucleosomes with the PRE. Interestingly, this is not the only alteration in nucleosome association evident in these transgenes. In all three of the multimer- $b x d$ PRE combinations, we found that histone $\mathrm{H} 3$ association with the more distant sequences $(1 \mathrm{n}, 2 \mathrm{n}$, $5 \mathrm{n}$, and $6 \mathrm{n}$ ) is enhanced relative to the various control transgenes (E-w, bxd and Su, CTCF, and Pita). Since enhanced association is not observed with the inactive $b x d$ PRE or with any of the multimers alone, it seems likely that this effect is due to the recruitment of functional PcG complexes to the $b x d$ PRE. It remains to be determined whether this alteration in histone $\mathrm{H} 3$ association reflects an increase in nucleosome density in the flanking DNA regions or an increase in the extent of compaction.

\section{Interplay between PREs and boundary contributes to silencing}

The studies in the previous sections indicate that boundaries can enhance PRE silencing by two different mechanisms. One takes place in cis and requires a close linkage of the boundary and PRE. This mechanism locally alters the pattern of histone association and facilitates the recruitment of factors critical for PcG repression. The other takes place in trans and is mediated by boundary:boundary pairing interactions. In this second mechanism, boundaries appear to provide a "spot weld" that holds the homologs in close proximity. This facilitates PRE:PRE interactions and results in PSS even when the boundary multimers are separated from the PREs. We undertook several additional experiments to further explore this "pairing" mechanism.

Boundary pairing can induce silencing in trans: When $4 \mathrm{xSu}(\mathrm{Hw})$ or $4 \mathrm{xCTCF}$ is placed next to the bxdPRE, the PRE can assemble a functional silencing complex and repress white in hemizygotes. However, the $b x d \mathrm{PRE}$ would not be expected to efficiently silence white in trans unless the homologs are tightly paired in the immediate neighborhood. To test this expectation, we generated trans-heterozygotes between the starting transgene E-w (the eye enhancer-white gene control construct which has all of the elements in the bxd construct except bxdPRE) and either Su-bxd or CTCF-bxd (Fig. 8a). While the $b x d \mathrm{PRE}$ silences the white gene in cis (Fig. 8aII, Su-bxd/+ and CTCF-bxd/+ - compare with E-w/+ in Fig. 8a-I), it does not efficiently silence the white gene in trans (Fig.8a-III, Su-bxd/E-w, and CTCF-bxd/E-w: compare with E-w/+ and E-w/E-w in Fig. 8a-I). In these two combinations, the eye color phenotype is indistinguishable from that observed in E-w /+ or E-w/E-w. A different result is obtained when both transgenes have a copy of the same multimer (Su-bxd/Su or CTCF-bxd/CTCF, Fig. 8a-IV-compare with Su-bxd/E-w and CTCF-bxd/ E-w, Fig.8a-III). While silencing is not as effective as when the two transgenes not only have identical multimers but also a copy of the $b x d$ PRE (see Fig. $8 \mathrm{a}-\mathrm{V}, \mathrm{Su}-$ bxd/Su-bxd, CTCF-bxd/CTCF-bxd), the level of white expression is clearly reduced compared to that observed when the multimer is not present in the $\mathrm{E}-\mathrm{w}$ transgene. This finding indicates that boundary:boundary pairing interactions can promote trans silencing by a PRE. To confirm that pairing interactions between the boundaries in the two transgenes provide a "spot weld" that facilitates trans silencing activity, we tested heterologous multimer combinations that do not pair with each other. As shown in Fig. 8a-VI, silencing is not observed with the Su-bxd/CTCF combination, nor is it observed with the converse CTCF-bxd/Su combination.

Boundary pairing is not necessary when both PREs are active: Placing multimerized binding sites for zinc finger architectural proteins next to the bxdPRE induces the assembly of functional silencing complexes in hemizygous flies and enhances PSS in homozygous flies. If the PREs on both homologs are activated by multimerized binding sites, then boundary:boundary pairing interactions would not be expected to be required for generating the synergistic trans interactions between PREs on each homolog that are responsible for PSS. To test this prediction, we generated trans combinations of bxdPRE transgenes that have closely linked multimerized $\mathrm{Su}(\mathrm{Hw}), \mathrm{CTCF}$, or Pita-binding sites. Figure 9a-II shows that the silencing of white in the three trans-heterologous combinations of multimerized binding sites is close to that observed when both transgenes have multimerized binding sites for the same protein.

An inactive PRE can be transactivated by an active PRE: The $b x d$ PRE insertion in the 22A attP site is a classic example of PSS. Little or no silencing is observed in hemizygotes, while silencing is quite efficient in homozygotes. The PSS phenomenon suggests that PRE:PRE 


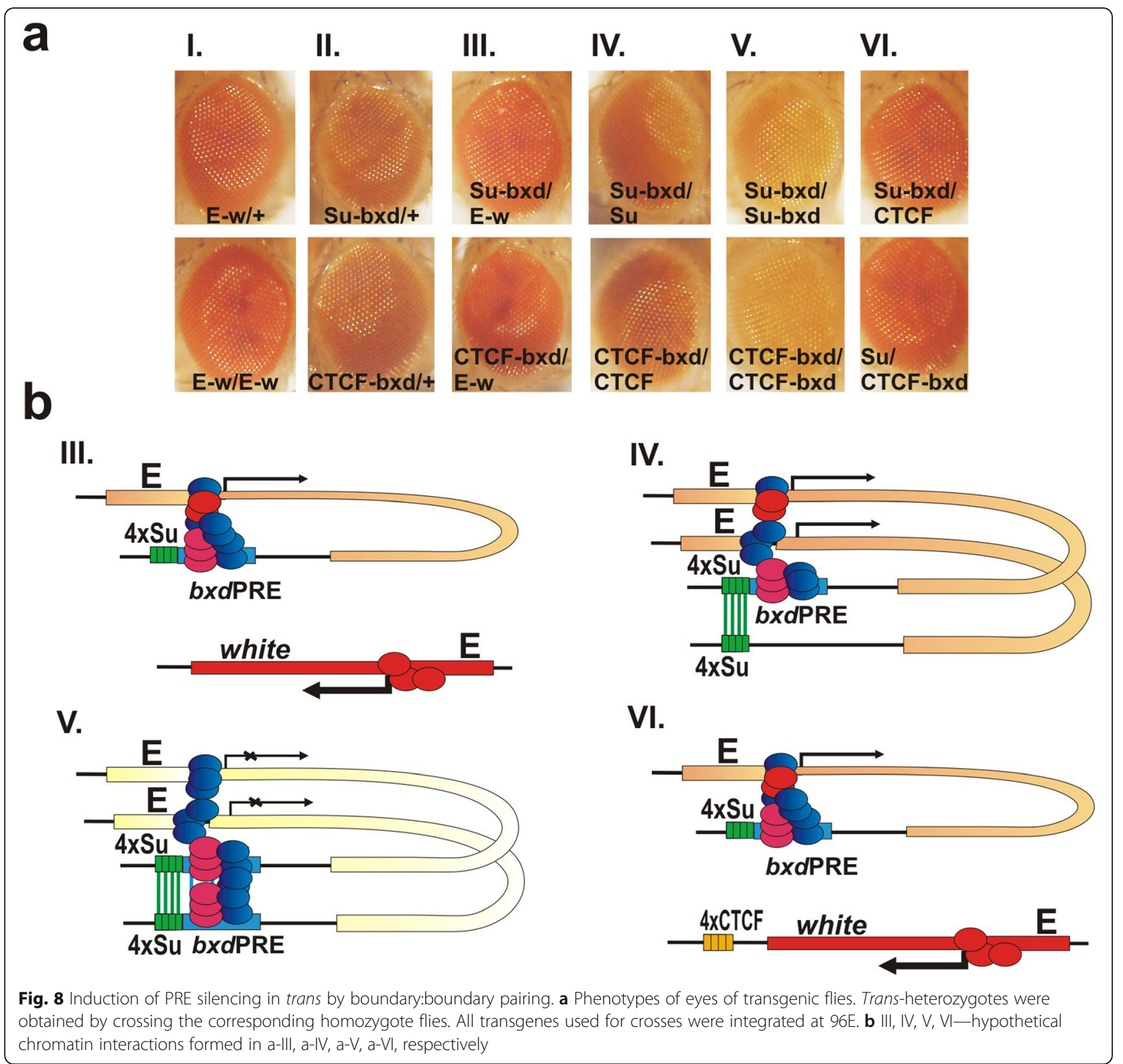

interactions in trans can synergizes, promoting the assembly of functional PcG silencing complexes on both PREs. To test this idea for 96E, we generated trans combinations between the inactive PRE in the bxd transgene and transgenes in which $b x d \mathrm{PRE}$ is activated by closely linked $4 \mathrm{xSu}(\mathrm{Hw}), 4 \mathrm{xCTCF}$, or $5 x$ Pita sites. Consistent with prediction, the white reporter in the homolog carrying the $b x d \mathrm{PRE}$ (only) transgene is repressed when the other homolog has the boundary-bxdPRE (compare eyes in Fig. 9a-III with those in Fig. 9a-IV). However, silencing is not equivalent to that observed when the bxdPREs on both homologs are activated by multimerized binding sites (Fig. 9a-I).

\section{Discussion}

PcG-dependent silencing is widely used during the development of multicellular organisms as a mechanism for maintaining the determined state [4-10]. In flies, PREs are responsible for recruiting the PcG complexes, PRC1, PRC2, and PhoRC, to repress transcription of their target genes [26-29]. Since PREs are able to establish and maintain silencing at ectopic locations in transgene assays, it is possible to study some of the parameters that govern their activities. In order to better control the chromosomal context, we selected five attP sites $(22 \mathrm{~A}, 51 \mathrm{C}, 58 \mathrm{~A}, 68 \mathrm{E}$, and $96 \mathrm{E})$ that appear to be "neutral" with respect to their effects on white 


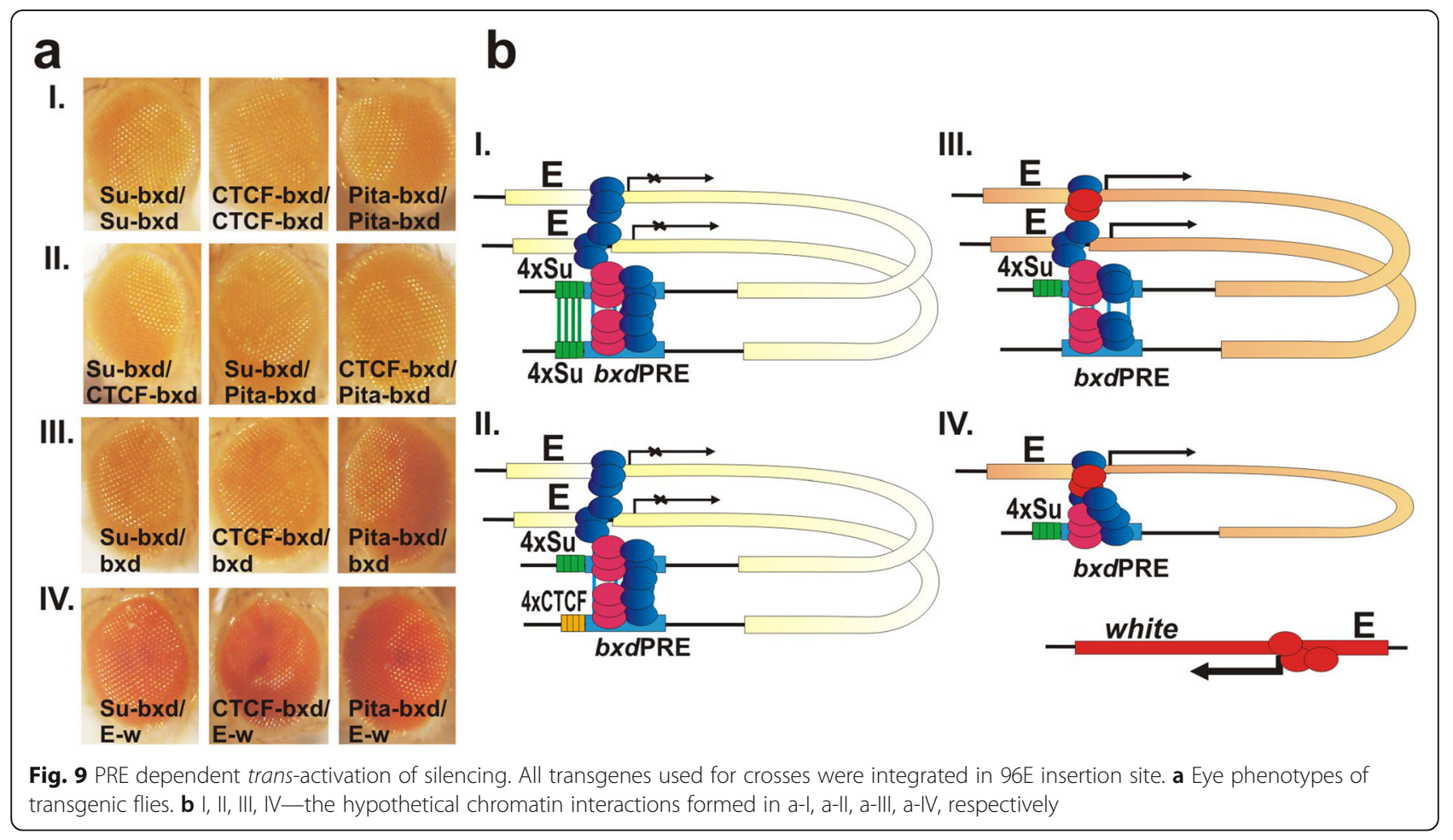

expression. Unexpectedly, in spite of this apparent homogeneity, the silencing activity of the $b x d$ PRE differs substantially from one site to the next. At one extreme $(68 \mathrm{E})$, strong silencing of white is observed in hemizygotes, while at the other extreme (96E) there is no evidence of silencing even in homozygotes. For the three remaining attP sites, there is a range of silencing in hemizygous and homozygotes. For $22 \mathrm{~A}$ and 58A, there is little evidence of silencing in hemizygous flies, while PSS is observed in homozygotes. In the case of $51 \mathrm{C}$, white expression is clearly repressed in hemizygotes, and repression increases in homozygotes. The strength of silencing at the five attP sites correlates well with the recruitment of the PcG protein Ph. High levels are found associated with $b x d \mathrm{PRE}$ when it is inserted at $68 \mathrm{E}$, while only background levels are evident at $96 \mathrm{E}$.

These findings are consistent with previous P-element transgene-based experiments, which showed that the silencing activity of PREs is non-autonomous and depends upon the local chromosomal context [42, 44-46]. The fact that $\mathrm{Ph}$ is not detected at $96 \mathrm{E}$ suggests that the establishment of silencing depends upon whether DNA binding proteins and PcG complexes can gain access to the PRE sequences at the site of the transgene insertion. Consistent with this idea, we found that like $\mathrm{Ph}$ several key PcG proteins are not associated with the $b x d$ PRE insert at $96 \mathrm{E}$.

These findings led us to wonder what features of the chromatin landscape in the neighborhood of the PRE might facilitate the recruitment of the required silencing factors. In this respect, it was of interest that PREs in BX-C are often closely linked to chromatin boundary elements [1]. This correlation suggested that boundary elements might be able to mediate the reorganization of the chromatin so that key silencing factors can gain access to the PRE. We tested this possibility by placing multimerized binding sites for three different chromosomal architectural proteins, $\mathrm{Su}(\mathrm{Hw}), \mathrm{CTCF}$, and Pita, adjacent to the $b x d$ PRE. We found that all three of these artificial boundaries were able to induce silencing in hemizygotes and PSS in homozygotes. For the $4 \mathrm{xSu}(\mathrm{Hw})-b x d \mathrm{PRE}$ combination, we found that the acquisition of silencing activity is accompanied by the recruitment of both components of the PhoRC DNA binding complex, Pho and Sfmbt, and other PcG silencing factors to the $b x d \mathrm{PRE}$. Surprisingly, we found that two TrxG proteins, Trx and CBP, are also associated with the $b x d$ PRE, and like the PcG factors, this association is only observed when the $b x d \mathrm{PRE}$ is closely linked to the $4 \mathrm{xSu}(\mathrm{Hw})$ multimer.

In hemizygotes, silencing activity is induced when the boundary multimers are placed next to the bxdPRE. Induction of silencing is distance dependent, and for the $4 \mathrm{xSu}(\mathrm{Hw})$ multimer, a distance of $1 \mathrm{~kb}$ is sufficient to largely eliminate silencing in hemizygotes, while it is reduced but not entirely eliminated for the $4 \mathrm{xCTCF}$ multimer. The importance of proximity taken together with the de novo recruitment of DNA binding and PcG 
proteins suggests that the boundary might alter the local chromatin structure so that factors important for PcGdependent silencing can gain access to the PRE. Consistent with this hypothesis, we find that multimerized binding sites for the boundary factors $\mathrm{Su}(\mathrm{Hw}), \mathrm{CTCF}$, and Pita can, on their own, generate a local reduction in histone H3 occupancy, indicating that the multimers likely form a nucleosome-free region of chromatin like that observed for many endogenous boundaries [90-92]. When the $b x d \mathrm{PRE}$ is placed next to these multimers, the nucleosome free region extends across the 650-bp $b x d$ PRE fragment. While we did not investigate the mechanisms of nucleosome displacement, $\mathrm{Su}(\mathrm{Hw})$ and CTCF have been shown to interact with chromatin remodeling complexes. $\mathrm{Su}(\mathrm{Hw})$ was found to recruit the Brahma chromatin remodeling protein [92], while both $\mathrm{Su}(\mathrm{Hw})$ and $\mathrm{CTCF}$ co-immunoprecipitate subunits of the NURF remodeling complex [93, 94]. Moreover, when CTCF is targeted to polytene chromosomes via linkage to the GAL4 DNA-binding domain, local chromatin decondensation is observed [95]. It would be reasonable to think that recruitment of these remodeling factors to the boundary multimers would in turn facilitate the displacement of nucleosomes from the PRE, enabling PcG (and TrxG) factors to gain access. Interestingly, activation of PcG silencing results in an increase in nucleosome density in the sequences flanking the PRE and the multimers. Since this phenomenon is not observed with the multimers alone, it seems possible that this change in nucleosome organization may be linked to PcGdependent silencing.

Consistent with idea that the boundary multimers facilitate the displacement of nucleosomes from the PRE, we find that silencing activity is compromised when the multimers are placed at a distance of 1 to $3 \mathrm{~kb}$ from the PRE. This distance effect would seem to argue against a mechanism in which the multimers target the PRE to a PcG compartment. On the other hand, while the boundary multimers are unable to fully augment silencing activity in hemizygotes unless they are next to the $b x d \mathrm{PRE}$, the presence of multimers in the transgene even at a distance of $3 \mathrm{~kb}$ is sufficient to promote PSS when the transgene is homozygous. Critically, the induction of PSS in this configuration is dependent on the ability of the boundaries on each homolog to pair with each other as it is not evident when the $4 \mathrm{xSu}(\mathrm{Hw})$ multimer is trans to the $4 \mathrm{xCTCF}$ multimer. A plausible interpretation of this finding is that when inactive PREs on each homolog are brought into close proximity by the paired boundaries, there is a synergistic interaction, which is able to promote the acquisition of PcG-dependent silencing activity. This model predicts that an active PRE should be able to trans-activate an inactive PRE. Consistent with this prediction, we found that an active $b x d \mathrm{PRE}$ (linked to a multimer) on one homolog can partially trans-activate an inactive $b x d$ PRE (unlinked to a multimer) on the other homolog.

\section{Conclusions}

Here, we show that boundary elements can help induce the silencing activity of PREs by facilitating the recruitment of DNA-binding and PcG/TrxG proteins. Unlike the $b x d$ PRE, the artificial boundaries we tested are able to autonomously establish regions of chromatin that have reduced nucleosome occupancy. When the $b x d \mathrm{PRE}$ is placed next to one of these multimers, the region of reduced nucleosome occupancy extends over the PRE. Accompany this reduction in occupancy, PcG and TrxG factors are found associated with the $b x d$ PRE and silencing activity is observed. In addition to this local effect on PcG silencing activity, we found that boundaries can induce PSS when placed at a distance from the PRE. In this case, our genetic experiments indicate that boundary:boundary pairing forms a "spot weld" which enables the PREs on each homolog to interact with each other and induce PcG silencing.

\section{Methods \\ Drosophila strains, germline transformation, and genetic crosses}

All flies were maintained at $25^{\circ} \mathrm{C}$ on the standard yeast medium. The constructs were injected into embryos of lines ZH-attP-22A (BDSC \#24481), ZH-attP-51C (BDSC \#24482), ZH-attP-58A (BDSC \#24484), ZH-attP-68E (BDSC \#24485), and ZH-attP-96E (BDSC \#24487) [60]. The resulting flies were crossed with $y a c w^{1118}$ flies, and the transgenic progeny was identified by their eye pigmentation. Details of crosses used for genetic analysis are given in Additional file 4.

For phenotype analysis of white expression, we visually determined the degree of pigmentation in the eyes (white) of 3- to 5-day-old males developing at $25^{\circ} \mathrm{C}$, with reference to standard color scales. Pigmentation of all flies was analyzed in hemi- $(\mathrm{P} /+)$ or homozygotes $(\mathrm{P} / \mathrm{P})$.

\section{Plasmid construction}

The BamHI-EcoRI fragment containing the white gene (mini-white version) without Wari insulator was clones from pCaSpeR $\Delta 700$ vector [96] into the pBluescript SK+ vector to obtain white-rev-pSK plasmid. The attB site was PCR-amplified with $5^{\prime}$-gtcgacgatgtaggtcacgg- $3^{\prime}$ and $5^{\prime}$-gtcgacatgcccgccgtgac-3' primers and cloned downstream of the white gene (attBdir-white-rev-pSK). The sequence corresponding to the eye enhancer $(E)$ of the white gene (regulatory sequences from position -1180 to -1849 bp relative to the transcription start site) was cut out of the Ee- pBluescript SK+ plasmid [63] without 
flanking sequences and cloned in direct orientation upstream of the white gene (attBdir-white-rev-E-rev-pSK).

The coding regions of eGFP (PCR-amplified with primers 5'-atggtgagcaagggcgaggagct- $3^{\prime}$ and $5^{\prime}$-cttgtacagctcgtccatgccga-3') and Cherry (PCR-amplified with primers $5{ }^{\prime}$-atggtgagcaagggcgaggag-3 and $5{ }^{\prime}$-ttacttgtacagctcgtccat-3') were cloned into pBluescript SK+ vector in a "head-to-head" orientation (eGFPrev-Cherry-pSK). The SV40 and yellow gene terminators of transcription were cloned downstream eGFP and Cherry respectively in orientation to stop the transcription from flanking regions (SV40dir-eGFPrev-Cherrydir-Ytermrev).

To obtain E-w construct, the fragment corresponding to SV40dir-eGFPrev-Cherrydir-Ytermrev was cloned into attBdir-white-rev-E-rev-pSK plasmid between attB and the white gene. The resulting $\mathrm{E}-\mathrm{w}$ construct has Bam $H I$ cloning site between the eGFP and RFP coding regions that was used to create the following constructs. The 656bp bxdPRE (corresponding to the genome sequences between PstI-NdeI) was PCR amplified from the frt(PRE) plasmid [97] with direct primer (5'-aaaagatctctcgagaaactagtgaggcagcgactgcgc-3' having $B g l \mathrm{II}, \mathrm{XhoI}$, and SpeI restriction sites) and reverse primer (5'-ttggatccgatagcttgatgatccaac-' having additional Bam HI site). The $b x d$ PRE PCR fragment was then cleaved by BamHI-BglII and cloned into E-w cleaved by BamHI (bxd construct). The $4 \mathrm{xSu}(\mathrm{Hw})$ sites $(4 \mathrm{xSu})$ were cut from a plasmid used previously [98] and cloned into the bxd construct cleaved by XhoI and SpeI (Su-bxd construct) or into the E-w construct cleaved by BamHI (Su construct). CTCF-bxd, CTCF, Pita-bxd, Pita, en, and Su-en constructs were generated by the same scheme using the following plasmids and fragments. The plasmids with 4xCTCF [75] and 5xPita [76] sites were kindly provided by Olga Kyrchanova. A 188-bp fragment containing the enPRE was PCR-amplified using $5{ }^{\prime}-$ gagatggcatgtggctctc- $3^{\prime}$ and $5^{\prime}$-attatgcgcatgctggagctgtc-3' primers. To create Su-1kb-bxd, CTCF-1kb-bxd constructs, the $\mathrm{Sph} I$ restriction site was inserted upstream of eGFP (SphI-bxd). The 4xSu fragment or 4xCTCF was inserted into SphI-bxd cleaved by SphI. To create Su-3kb-bxd, CTCF$3 \mathrm{~kb}$-bxd constructs, the 2087-bp fragment containing the LacZ coding region was inserted into Su-1kb-bxd, CTCF$1 \mathrm{~kb}$-bxd constructs between $4 \mathrm{xSu}$ and eGFP. The sequences corresponding to construct fragments (attB, SV40 terminator, eGFP, 4xSu, 4xCTCF, 5xPita, bxdPRE, enPRE, Cherry, Yterm, white, and E) are given in Additional file 4.

\section{Chromatin immunoprecipitation (X-ChIP)}

For each experiment, 150-200 $\mathrm{mg}$ of heads from 2- to 5-day-old adults homozygous for the different constructs were collected. Experimental procedures for chromatin immunoprecipitations were performed as described previously $[62,63]$. Briefly, the material was homogenized in $5 \mathrm{ml}$ of buffer A1 (15 mM HEPES, pH 7.6; $60 \mathrm{mM}$ $\mathrm{KCl}, 15 \mathrm{mM} \mathrm{NaCl}, 4 \mathrm{mM} \mathrm{MgCl} 2,0.5 \%$ Triton X-100,
$0.5 \mathrm{mM}$ DTT) supplemented with the EDTA-free protease inhibitor cocktail (Roche, Switzerland) and formaldehyde as a crosslinking agent (final concentration 1.8\%). The reaction was stopped by adding glycine (final concentration $225 \mathrm{mM}$ ). The homogenate was cleared by passing through $100-\mu \mathrm{m}$ nylon cell strainer (BD Falcon) and pelleted by centrifugation at $4000 \mathrm{~g}, 4^{\circ} \mathrm{C}$ for $5 \mathrm{~min}$. After washing in three 3-ml portions of buffer $\mathrm{A} 1$ at $4^{\circ} \mathrm{C}$ (5 min each) and $3 \mathrm{ml}$ of lysis buffer without SDS, the pellet was treated with $0.5 \mathrm{ml}$ of complete lysis buffer (15 mM HEPES, pH 7.6; $140 \mathrm{mM} \mathrm{NaCl}, 1 \mathrm{mM}$ EDTA, 0.5 mM EGTA, 1\%Triton X-100, 0.5 mM DTT, $0.1 \%$ sodium deoxycholate, $0.1 \%$ SDS, $0.5 \% N$-lauroylsarcosine, EDTA-free protease inhibitor cocktail) and sonicated to break chromatin into fragments with an average length of $700 \mathrm{bp}$. The material was pelleted by centrifugation at $18000 \mathrm{~g}$ for $5 \mathrm{~min}$, and the supernatant fluid was transferred to a new tube. The pellet was treated with the second $0.5-\mathrm{ml}$ portion of lysis buffer, and the preparation was centrifuged at $18000 \mathrm{~g}$ for $5 \mathrm{~min}$. The two portions of the supernatant fluid were pooled, cleared by centrifuging twice at $18000 \mathrm{~g}$ for $10 \mathrm{~min}$, and the resultant chromatin extract $(1 \mathrm{ml})$ was used for ChIP experiments after preincubation with A-Sepharose or GSepharose. One aliquot (1/10 volume) of chromatin extract after preincubation with Sepharose was kept as a control sample (Input).

ChIP experiments involved incubation with specific rabbit/rat antibodies or with nonimmune IgG that was used as nonspecific antibody control. All ChIP experiments were made at least in triplicate. The enrichment of specific DNA fragments was analyzed by real-time qPCR, using a C1000 ${ }^{\text {ma }}$ Thermal Cycler with CFX96 realtime PCR detection module (Bio-Rad) or a StepOne Plus Thermal Cycler (Applied Biosystems, USA). Primers used in ChIP/real-time PCR analyses are listed in Additional file 1: Table S2 and Table S3.

\section{Antibodies}

Antibodies against $\mathrm{Ph}$ (86-520 aa, ph-p, isoform PA), Sfmbt (1-348 aa of isoform PB) [62, 63], and Trx-N (8-351 aa of isoform PA) [62] were raised in rabbits and described previously. Antibodies against Combgap (31-269aa of isoform PF) and CBP (1-290 aa of isoform PB) were raised in rabbits. Pho (full length of isoform PA) was raised in rats. Antigens for antibody production were expressed as a $6 \times$ His-tagged fusion proteins in Escherichia coli, affinity purified on Ni Sepharose 6 Fast Flow (GE Healthcare) according to the manufacturer's protocol and injected into rabbits following the standard immunization procedure. Antibodies were affinity-purified from serum on the same antigen as was used for immunization. The specificity of Combgap, CBP, and Pho antibodies was verified by RNAi/Western blotting (Additional file 1: Figure 
S2) according to protocol described previously [99]. Antilamin ADL67.10 antibodies were provided by the Developmental Studies Hybridoma Bank (deposited to the DSHB by Fisher, P. A., DSHB Cat\# adl67.10, RRID:AB_ 528336). For nucleosome, ChIP commercial antibodies (Abcam Cat\# ab1791, RRID:AB_302613) were used.

\section{Supplementary Information}

The online version contains supplementary material available at https://doi. org/10.1186/s12915-021-01047-8.

Additional file 1: Table S1. Eye phenotypes of hemizygote transgene flies with insertion of white marker gene without enhancer at selected attP lines. Figure S1. X-ChIP for the "Su" transgene with Ph antibody and X-ChIP for the "Su-bxd" and "Su" transgenes with Su(Hw) antibody. Table S2. Primers used for X-ChIP-qPCR analysis to test PCG/TrxG, DNA-binding proteins recruitment to transgenes. Table S3. Primers used for X-ChIPqPCR analysis to test histone $\mathrm{H3}$ binding to transgenes. Figure S2. Antibody specificity test.

Additional file 2. This file contains the analysis of homologue chromosomes contact frequencies at the 22A, 51C, 58A, 68E and 96E attP insertion sites.

Additional file 3. This file contains the ChIP-seq data for PCG and boundary proteins binding to 22A, 51C, 58A, 68E and 96E genome regions.

Additional file $\mathbf{4}$ This file contains: (1) the DNA sequences of the construct elements. (2) the details of Drosophila genetic crosses.

\section{Acknowledgements}

We thank the Center for Precision Genome Editing and Genetic Technologies for Biomedicine, IGB RAS, for the required equipment. We thank Olga Kyrchanova for the plasmids with 4xCTCF and 5xPita.

\section{Authors' contributions}

Conception and design of the project: M.E, P.G., P.S., and D.C. Flies handing and crosses-M.E, F.G., and D.L.; plasmid construction-M.E, F.G., D.L., and D.C.; embryo injections-A.P.; X-ChIP experiments-M.E. and F.G.; Combgap, CBP, and Pho antigen cloning and expression, antibodies production, purification, and verification-M.E, D.L., M.Y.M., A.M, N.E.V., and D.C. Hi-C data analysis-A.K.G. The initial draft of this manuscript was written by M.E, P.S., and D.C, reviewed and edited by M.E, P.S., and D.C. The authors read and approved the final manuscript.

\section{Funding}

Authors would like to acknowledge the support from the following grants. The antibodies productions and X-ChIP experiments were made by support from RSF [18-74-10091 to D.C]. Plasmid constructions and genetic experiments were made with the support from the RFBR [18-04-00798 to D.C.], and P.S. would like to acknowledge support from NIH [5R35GM126975].

\section{Availability of data and materials}

All relevant data are within the paper and its Supporting Information.

\section{Declarations}

\section{Ethics approval and consent to participate}

Animal handling for the antibody production was carried out strictly according to the procedures outlined in the NIH (USA) Guide for the Care and Use of Laboratory Animals. The protocols used were approved by the Committee on Bioethics of the Institute of Gene Biology, Russian Academy of Sciences. All procedures were performed under the supervision of a licensed veterinarian, under conditions that minimize pain and distress. Rabbits were purchased from a licensed specialized nursery, and Manihino. Soviet chinchilla rabbits used in the study are not endangered or protected. Only healthy rabbits certified by a licensed veterinarian were used. The rabbits were individually housed in standard size, stainless steel rabbit cages and provided ad libitum access to alfalfa hay, commercial rabbit food pellets, and water. The appetite and behavior of each rabbit were monitored daily by a licensed veterinarian. Body weight and temperature of each rabbit were evaluated prior to and daily following immunization. No animals became ill or died at any time prior to the experimental endpoint. At the end of the study period, all rabbits were euthanized by intravenous injection of barbiturate anesthetics.

\section{Consent for publication}

Not applicable.

\section{Competing interests}

The authors declare that they have no competing interests.

\section{Author details}

${ }^{1}$ Group of Chromatin Biology, Institute of Gene Biology, Russian Academy of Sciences, 34/5 Vavilov St., Moscow 119334, Russia. ${ }^{2}$ Present address: Department of Biology, ETH Zurich, Zurich, Switzerland. ${ }^{3}$ Group of Epigenetics, Institute of Gene Biology, Russian Academy of Sciences, 34/5 Vavilov St., Moscow 119334, Russia. ${ }^{4}$ Group of Transcriptional Complexes Dynamics, Institute of Gene Biology, Russian Academy of Sciences, Moscow, Russia. ${ }^{5}$ Laboratory of Structural and Functional Organization of Chromosomes, Institute of Gene Biology, Russian Academy of Sciences, 34/5 Vavilov St., Moscow 119334, Russia. ${ }^{6}$ Department of the Control of Genetic Processes, Institute of Gene Biology, Russian Academy of Sciences, 34/5 Vavilov St., Moscow 119334, Russia. ${ }^{7}$ Department of Molecular Biology Princeton University, Princeton, NJ 08544, USA

Received: 11 February 2021 Accepted: 7 May 2021

Published online: 02 June 2021

\section{References}

1. Kyrchanova O, Mogila V, Wolle D, Magbanua JP, White R, Georgiev P, et al. The boundary paradox in the bithorax complex. Mech Dev. 2015;138(Pt 2): 122-32 https://doi.org/10.1016/j.mod.2015.07.002.

2. Lewis EB. A gene complex controlling segmentation in Drosophila. Nature. 1978;276(5688):565-70 https://doi.org/10.1038/276565a0.

3. Maeda RK, Karch F. The open for business model of the bithorax complex in Drosophila. Chromosoma. 2015. https://doi.org/10.1007/s00412-015-0522-0; 124(3):293-307.

4. Brand M, Nakka K, Zhu J, Dilworth FJ. Polycomb/trithorax antagonism: cellular memory in stem cell fate and function. Cell Stem Cell. 2019;24(4): 518-33 https://doi.org/10.1016/j.stem.2019.03.005.

5. Chetverina DA, Elizar'ev PV, Lomaev DV, Georgiev PG, Erokhin MM. Control of the gene activity by polycomb and trithorax group proteins in Drosophila. Genetika. 2017;53(2):133-54.

6. Geisler SJ, Paro R. Trithorax and polycomb group-dependent regulation: a tale of opposing activities. Development. 2015;142(17):2876-87 https://doi. org/10.1242/dev.120030.

7. Kassis JA, Kennison JA, Tamkun JW. Polycomb and Trithorax Group Genes in Drosophila. Genetics. 2017;206(4):1699-725 https://doi.org/10.1534/ genetics.115.185116.

8. Kuroda MI, Kang H, De S, Kassis JA. Dynamic competition of polycomb and trithorax in transcriptional programming. Annu Rev Biochem. 2020. https:// doi.org/10.1146/annurev-biochem-120219-103641;89(1):235-53.

9. Schuettengruber B, Bourbon HM, Di Croce L, Cavalli G. Genome regulation by polycomb and trithorax: 70 years and counting. Cell. 2017;171(1):34-57 https://doi.org/10.1016/j.cell.2017.08.002

10. Steffen PA, Ringrose $L$. What are memories made of? How polycomb and trithorax proteins mediate epigenetic memory. Nat Rev Mol Cell Biol. 2014; 15(5):340-56 https://doi.org/10.1038/nrm3789.

11. Chammas P, Mocavini I, Di Croce L. Engaging chromatin: PRC2 structure meets function. Br J Cancer. 2020;122(3):315-28 https://doi.org/10.1038/ s41416-019-0615-2.

12. Chan $\mathrm{HL}$, Morey L. Emerging roles for polycomb-group proteins in stem cells and cancer. Trends Biochem Sci. 2019;44(8):688-700 https://doi.org/1 0.1016/j.tibs.2019.04.005

13. Comet I, Riising EM, Leblanc B, Helin K. Maintaining cell identity: PRC2mediated regulation of transcription and cancer. Nat Rev Cancer. 2016; 16(12):803-10 https://doi.org/10.1038/nrc.2016.83. 
14. Laugesen A, Hojfeldt JW, Helin K. Molecular mechanisms directing PRC2 recruitment and H3K27 methylation. Mol Cell. 2019;74(1):8-18 https://doi. org/10.1016/j.molcel.2019.03.011.

15. Zhao Z, Shilatifard A. Epigenetic modifications of histones in cancer. Genome Biol. 2019;20(1):245 https://doi.org/10.1186/s13059-019-1870-5.

16. Piunti A, Shilatifard A. Epigenetic balance of gene expression by polycomb and COMPASS families. Science. 2016;352(6290):aad9780 https://doi.org/1 $0.1126 /$ science.aad9780.

17. Francis NJ, Saurin AJ, Shao Z, Kingston RE. Reconstitution of a functional core polycomb repressive complex. Mol Cell. 2001;8(3):545-56. https://doi. org/10.1016/S1097-2765(01)00316-1.

18. Saurin AJ, Shao Z, Erdjument-Bromage H, Tempst P, Kingston RE. A Drosophila polycomb group complex includes Zeste and dTAFIl proteins. Nature. 2001;412(6847):655-60 https://doi.org/10.1038/35088096.

19. Shao Z, Raible F, Mollaaghababa R, Guyon JR, Wu CT, Bender W, et al. Stabilization of chromatin structure by PRC1, a Polycomb complex. Cell. 1999;98(1):37-46 https://doi.org/10.1016/S0092-8674(00)80604-2.

20. Czermin B, Melfi R, McCabe D, Seitz V, Imhof A, Pirrotta V. Drosophila enhancer of Zeste/ESC complexes have a histone $\mathrm{H} 3$ methyltransferase activity that marks chromosomal Polycomb sites. Cell. 2002;111(2):185-96. https://doi.org/10.1016/50092-8674(02)00975-3.

21. Muller J, Hart CM, Francis NJ, Vargas ML, Sengupta A, Wild B, et al. Histone methyltransferase activity of a Drosophila polycomb group repressor complex. Cell. 2002;111(2):197-208. https://doi.org/10.1016/S0092-8674(02 )00976-5.

22. Klymenko T, Papp B, Fischle W, Kocher T, Schelder M, Fritsch C, et al. A polycomb group protein complex with sequence-specific DNA-binding and selective methyl-lysine-binding activities. Genes Dev. 2006;20(9):1110-22 https://doi.org/10.1101/gad.377406

23. Fritsch C, Brown JL, Kassis JA, Muller J. The DNA-binding polycomb group protein pleiohomeotic mediates silencing of a Drosophila homeotic gene. Development. 1999;126(17):3905-13. https://doi.org/10.1242/dev.126.17.3905.

24. Kingston RE, Tamkun JW. Transcriptional regulation by trithorax-group proteins. Cold Spring Harb Perspect Biol. 2014;6(10):a019349 https://doi. org/10.1101/cshperspect.a019349.

25. Schuettengruber B, Martinez AM, lovino N, Cavalli G. Trithorax group proteins: switching genes on and keeping them active. Nat Rev Mol Cell Biol. 2011;12(12):799-814 https://doi.org/10.1038/nrm3230.

26. Bauer M, Trupke J, Ringrose $L$. The quest for mammalian Polycomb response elements: are we there yet? Chromosoma. 2015. https://doi.org/1 0.1007/s00412-015-0539-4;125(3):471-96.

27. Erokhin M, Georgiev P, Chetverina D. Drosophila DNA-binding proteins in polycomb repression. Epigenomes. 2018;2(1):1 https://doi.org/10.3390/ epigenomes2010001.

28. Kassis JA, Brown JL. Polycomb group response elements in Drosophila and vertebrates. Adv Genet. 2013;81:83-118 https://doi.org/10.1016/B978-0-12-4 07677-8.00003-8

29. McElroy KA, Kang H, Kuroda Ml. Are we there yet? Initial targeting of the Male-Specific Lethal and Polycomb group chromatin complexes in Drosophila. Open Biol. 2014;4(3):140006. https://doi.org/10.1098/rsob.140006.

30. Muller J, Bienz M. Long range repression conferring boundaries of Ultrabithorax expression in the Drosophila embryo. EMBO J. 1991;10(11): 3147-55. https://doi.org/10.1002/j.1460-2075.1991.tb04876.x

31. Orlando V, Jane EP, Chinwalla V, Harte PJ, Paro R. Binding of trithorax and Polycomb proteins to the bithorax complex: dynamic changes during early Drosophila embryogenesis. EMBO J. 1998;17(17):5141-50 https://doi.org/10.1 093/emboj/17.17.5141.

32. Fujioka M, Sun G, Jaynes JB. The Drosophila eve insulator Homie promotes eve expression and protects the adjacent gene from repression by polycomb spreading. PLoS Genet. 2013;9(10):e1003883 https://doi.org/10.13 71/journal.pgen.1003883.

33. Kassis JA. Unusual properties of regulatory DNA from the Drosophila engrailed gene: three "pairing-sensitive" sites within a 1.6-kb region. Genetics. 1994;136(3):1025-38. https://doi.org/10.1093/genetics/136.3.1025.

34. Brown JL, Fritsch C, Mueller J, Kassis JA. The Drosophila pho-like gene encodes a YY1-related DNA binding protein that is redundant with pleiohomeotic in homeotic gene silencing. Development. 2003;130(2):28594. https://doi.org/10.1242/dev.00204.

35. Ray P, De S, Mitra A, Bezstarosti K, Demmers JA, Pfeifer K, et al. Combgap contributes to recruitment of Polycomb group proteins in Drosophila. Proc
Natl Acad Sci U S A. 2016;113(14):3826-31 https://doi.org/10.1073/pnas.152 0926113.

36. Kassis JA. Pairing-sensitive silencing, polycomb group response elements, and transposon homing in Drosophila. Adv Genet. 2002;46:421-38. https:// doi.org/10.1016/S0065-2660(02)46015-4.

37. Mihaly J, Hogga I, Gausz J, Gyurkovics H, Karch F. In situ dissection of the Fab-7 region of the bithorax complex into a chromatin domain boundary and a Polycomb-response element. Development. 1997;124(9):1809-20. https://doi.org/10.1242/dev.124.9.1809.

38. Americo J, Whiteley M, Brown JL, Fujioka M, Jaynes JB, Kassis JA. A complex array of DNA-binding proteins required for pairing-sensitive silencing by a polycomb group response element from the Drosophila engrailed gene. Genetics. 2002;160(4):1561-71. https://doi.org/10.1093/genetics/160.4.1561.

39. Bloyer S, Cavalli G, Brock HW, Dura JM. Identification and characterization of polyhomeotic PREs and TREs. Dev Biol. 2003;261(2):426-42 https://doi.org/1 0.1016/s0012-1606(03)00314-2.

40. Fujioka M, Yusibova GL, Zhou J, Jaynes JB. The DNA-binding Polycombgroup protein Pleiohomeotic maintains both active and repressed transcriptional states through a single site. Development. 2008;135(24): 4131-9 https://doi.org/10.1242/dev.024554.

41. Horard B, Tatout C, Poux S, Pirrotta V. Structure of a polycomb response element and in vitro binding of polycomb group complexes containing GAGA factor. Mol Cell Biol. 2000;20(9):3187-97. https://doi.org/10.1128/ MCB.20.9.3187-3197.2000.

42. Noyes A, Stefaniuk C, Cheng Y, Kennison JA, Kassis JA. Modulation of the activity of a polycomb-group response element in Drosophila by a mutation in the transcriptional activator woc. G3 (Bethesda). 2011;1(6):471-8 https://doi.org/10.1534/g3.111.001230.

43. Okulski H, Druck B, Bhalerao S, Ringrose L. Quantitative analysis of polycomb response elements (PREs) at identical genomic locations distinguishes contributions of PRE sequence and genomic environment. Epigenetics Chromatin. 2011;4(1):4. https://doi.org/10.1186/1756-8935-4-4.

44. De S, Cheng Y, Sun MA, Gehred ND, Kassis JA. Structure and function of an ectopic Polycomb chromatin domain. Sci Adv. 2019;5(1):eaau9739 https:// doi.org/10.1126/sciadv.aau9739.

45. De S, Mitra A, Cheng Y, Pfeifer K, Kassis JA. Formation of a polycombdomain in the absence of strong polycomb response elements. PLoS Genet. 2016;12(7):e1006200 https://doi.org/10.1371/journal.pgen.1006200.

46. DeVido SK, Kwon D, Brown JL, Kassis JA. The role of Polycomb-group response elements in regulation of engrailed transcription in Drosophila. Development. 2008;135(4):669-76 https://doi.org/10.1242/dev.014779.

47. Chetverina D, Aoki T, Erokhin M, Georgiev P, Schedl P. Making connections: insulators organize eukaryotic chromosomes into independent cisregulatory networks. Bioessays. 2014;36(2):163-72 https://doi.org/10.1002/ bies.201300125.

48. Chetverina D, Fujioka M, Erokhin M, Georgiev P, Jaynes JB, Schedl P. Boundaries of loop domains (insulators): Determinants of chromosome form and function in multicellular eukaryotes. Bioessays. 2017;39(3) https://doi. org/10.1002/bies.201600233.

49. Srinivasan A, Mishra RK. Lessons on gene regulation learnt from the Drosophila melanogaster bithorax complex. Int J Dev Biol. 2020;64(1-2-3): 151-8 https://doi.org/10.1387/ijdb.190167rm.

50. Hagstrom K, Muller M, Schedl P. A Polycomb and GAGA dependent silencer adjoins the Fab-7 boundary in the Drosophila bithorax complex. Genetics. 1997;146(4):1365-80. https://doi.org/10.1093/genetics/146.4.1365.

51. Kyrchanova O, Kurbidaeva A, Sabirov M, Postika N, Wolle D, Aoki T, et al. The bithorax complex iab-7 Polycomb response element has a novel role in the functioning of the Fab-7 chromatin boundary. PLoS Genet. 2018;14(8): e1007442 https://doi.org/10.1371/journal.pgen.1007442.

52. Gruzdeva N, Kyrchanova O, Parshikov A, Kullyev A, Georgiev P. The Mcp element from the bithorax complex contains an insulator that is capable of pairwise interactions and can facilitate enhancer-promoter communication. Mol Cell Biol. 2005;25(9):3682-9 https://doi.org/10.1128/MCB.25.9.3682-3 689.2005.

53. Muller M, Hagstrom K, Gyurkovics H, Pirrotta V, Schedl P. The mcp element from the Drosophila melanogaster bithorax complex mediates longdistance regulatory interactions. Genetics. 1999;153(3):1333-56. https://doi. org/10.1093/genetics/153.3.1333.

54. Sigrist CJ, Pirrotta V. Chromatin insulator elements block the silencing of a target gene by the Drosophila polycomb response element (PRE) but allow 
trans interactions between PREs on different chromosomes. Genetics. 1997; 147(1):209-21. https://doi.org/10.1093/genetics/147.1.209.

55. Comet I, Schuettengruber B, Sexton T, Cavalli G. A chromatin insulator driving three-dimensional Polycomb response element (PRE) contacts and Polycomb association with the chromatin fiber. Proc Natl Acad Sci U S A. 2011;108(6):2294-9 https://doi.org/10.1073/pnas.1002059108.

56. Li HB, Muller M, Bahechar IA, Kyrchanova O, Ohno K, Georgiev P, et al. Insulators, not Polycomb response elements, are required for long-range interactions between Polycomb targets in Drosophila melanogaster. Mol Cell Biol. 2011;31(4):616-25 https://doi.org/10.1128/MCB.00849-10.

57. Comet I, Savitskaya E, Schuettengruber B, Negre N, Lavrov S, Parshikov A, et al. PRE-mediated bypass of two Su(Hw) insulators targets PCG proteins to a downstream promoter. Dev Cell. 2006;11(1):117-24 https://doi.org/10.101 6/j.devcel.2006.05.009.

58. Kapoun AM, Kaufman TC. Regulatory regions of the homeotic gene proboscipedia are sensitive to chromosomal pairing. Genetics. 1995;140(2): 643-58. https://doi.org/10.1093/genetics/140.2.643.

59. Kassis JA, VanSickle EP, Sensabaugh SM. A fragment of engrailed regulatory DNA can mediate transvection of the white gene in Drosophila. Genetics. 1991;128(4):751-61. https://doi.org/10.1093/genetics/128.4.751.

60. Bischof J, Maeda RK, Hediger M, Karch F, Basler K. An optimized transgenesis system for Drosophila using germ-line-specific phic31 integrases. Proc Natl Acad Sci U S A. 2007;104(9):3312-7 https://doi.org/10.1073/pnas.0611511104.

61. Chan CS, Rastelli L, Pirrotta V. A Polycomb response element in the Ubx gene that determines an epigenetically inherited state of repression. EMBO J. 1994;13(11):2553-64. https://doi.org/10.1002/j.1460-2075.1994.tb06545.x.

62. Erokhin M, Elizar'ev P, Parshikov A, Schedl P, Georgiev P, Chetverina D. Transcriptional read-through is not sufficient to induce an epigenetic switch in the silencing activity of Polycomb response elements. Proc Natl Acad Sci U S A. 2015;112(48):14930-5 https://doi.org/10.1073/pnas.1515276112.

63. Erokhin M, Davydova A, Parshikov A, Studitsky VM, Georgiev P, Chetverina D. Transcription through enhancers suppresses their activity in Drosophila. Epigenetics Chromatin. 2013;6(1):31 https://doi.org/10.1186/1756-8935-6-31.

64. AlHaj Abed J, Erceg J, Goloborodko A, Nguyen SC, McCole RB, Saylor W, et al. Highly structured homolog pairing reflects functional organization of the Drosophila genome. Nat Commun. 2019;10(1):4485 https://doi.org/10.1 038/s41467-019-12208-3.

65. Chetverina D, Erokhin M, Schedl P. GAGA factor: a multifunctional pioneering chromatin protein. Cell Mol Life Sci. 2021; https://doi.org/10.1 007/s00018-021-03776-z.

66. Mazo AM, Mizrokhi LJ, Karavanov AA, Sedkov YA, Krichevskaja AA, llyin YV. Suppression in Drosophila: su(Hw) and su(f) gene products interact with a region of gypsy (mdg4) regulating its transcriptional activity. EMBO J. 1989; 8(3):903-11. https://doi.org/10.1002/j.1460-2075.1989.tb03451.x.

67. Parkhurst SM, Harrison DA, Remington MP, Spana C, Kelley RL, Coyne RS, et al. The Drosophila su(Hw) gene, which controls the phenotypic effect of the gypsy transposable element, encodes a putative DNA-binding protein. Genes Dev. 1988;2(10):1205-15 https://doi.org/10.1101/gad.2.10.1205.

68. Harrison DA, Gdula DA, Coyne RS, Corces VG. A leucine zipper domain of the suppressor of Hairy-wing protein mediates its repressive effect on enhancer function. Genes Dev. 1993;7(10):1966-78 https://doi.org/10.1101/ gad.7.10.1966

69. Kim J, Shen B, Rosen C, Dorsett D. The DNA-binding and enhancer-blocking domains of the Drosophila suppressor of Hairy-wing protein. Mol Cell Biol. 1996;16(7):3381-92 https://doi.org/10.1128/mcb.16.7.3381.

70. Scott KC, Taubman AD, Geyer PK. Enhancer blocking by the Drosophila gypsy insulator depends upon insulator anatomy and enhancer strength. Genetics. 1999;153(2):787-98. https://doi.org/10.1093/genetics/153.2.787.

71. Kyrchanova O, Mogila V, Wolle D, Deshpande G, Parshikov A, Cleard F, et al. Functional dissection of the blocking and bypass activities of the Fab-8 boundary in the Drosophila bithorax complex. PLoS Genet. 2016;12(7): e1006188 https://doi.org/10.1371/journal.pgen.1006188.

72. Mallin DR, Myung JS, Patton JS, Geyer PK. Polycomb group repression is blocked by the Drosophila suppressor of Hairy-wing [su(Hw)] insulator. Genetics. 1998;148(1):331-9. https://doi.org/10.1093/genetics/148.1.331.

73. Brown $J$, Sun MA, Kassis JA. Global changes of H3K27me3 domains and Polycomb group protein distribution in the absence of recruiters Spps or Pho. Proc Natl Acad Sci U S A. 2018;115(8):E1839-E48 https://doi.org/10.1 073/pnas.1716299115.

74. Ramirez F, Bhardwaj V, Arrigoni L, Lam KC, Gruning BA, Villaveces J, et al. High-resolution TADs reveal DNA sequences underlying genome organization in flies. Nat Commun. 2018;9(1):189 https://doi.org/10.1038/ s41467-017-02525-w.

75. Kyrchanova O, Sabirov M, Mogila V, Kurbidaeva A, Postika N, Maksimenko O, et al. Complete reconstitution of bypass and blocking functions in a minimal artificial Fab-7 insulator from Drosophila bithorax complex. Proc Natl Acad Sci U S A. 2019;116(27):13462-7 https://doi.org/10.1073/pnas.1 907190116.

76. Kyrchanova O, Zolotarev N, Mogila V, Maksimenko O, Schedl P, Georgiev P. Architectural protein Pita cooperates with dCTCF in organization of functional boundaries in Bithorax complex. Development. 2017;144(14): 2663-72 https://doi.org/10.1242/dev.149815.

77. Kyrchanova O, Maksimenko O, Ibragimov A, Sokolov V, Postika N, Lukyanova $\mathrm{M}$, et al. The insulator functions of the Drosophila polydactyl $\mathrm{C} 2 \mathrm{H} 2$ zinc finger protein CTCF: necessity versus sufficiency. Sci Adv. 2020;6(13): eaaz3152 https://doi.org/10.1126/sciadv.aaz3152

78. Brown JL, Grau DJ, DeVido SK, Kassis JA. An Sp1/KLF binding site is important for the activity of a Polycomb group response element from the Drosophila engrailed gene. Nucleic Acids Res. 2005;33(16):5181-9 https:// doi.org/10.1093/nar/gki827.

79. Brown JL, Kassis JA. Spps, a Drosophila Sp1/KLF family member, binds to PREs and is required for PRE activity late in development. Development. 2010;137(15):2597-602 https://doi.org/10.1242/dev.047761.

80. Brown JL, Kassis JA. Architectural and functional diversity of polycomb group response elements in Drosophila. Genetics. 2013;195(2):407-19 https://doi.org/10.1534/genetics.113.153247.

81. Brown JL, Mucci D, Whiteley M, Dirksen ML, Kassis JA. The Drosophila Polycomb group gene pleiohomeotic encodes a DNA binding protein with homology to the transcription factor YY1. Mol Cell. 1998;1(7):1057-64. https://doi.org/10.1016/S1097-2765(00)80106-9.

82. Langlais KK, Brown $J$, Kassis JA. Polycomb group proteins bind an engrailed PRE in both the "ON" and "OFF" transcriptional states of engrailed. PLOS One. 2012;7(11):e48765 https://doi.org/10.1371/journal.pone.0048765.

83. Loubiere V, Martinez AM, Cavalli G. Cell fate and developmental regulation dynamics by polycomb proteins and 3D genome architecture. Bioessays. 2019;41(3):e1800222 https://doi.org/10.1002/bies.201800222.

84. Blanton J, Gaszner M, Schedl P. Protein:protein interactions and the pairing of boundary elements in vivo. Genes Dev. 2003;17(5):664-75 https://doi. org/10.1101/gad.1052003.

85. Kyrchanova O, Ivlieva T, Toshchakov S, Parshikov A, Maksimenko O, Georgiev $P$. Selective interactions of boundaries with upstream region of $A b d-B$ promoter in Drosophila bithorax complex and role of dCTCF in this process. Nucleic Acids Res. 2011;39(8):3042-52 https://doi.org/10.1093/nar/gkq1248.

86. Kyrchanova O, Toshchakov S, Podstreshnaya Y, Parshikov A, Georgiev P. Functional interaction between the Fab-7 and Fab-8 boundaries and the upstream promoter region in the Drosophila Abd-B gene. Mol Cell Biol. 2008;28(12):4188-95 https://doi.org/10.1128/MCB.00229-08.

87. Muravyova E, Golovnin A, Gracheva E, Parshikov A, Belenkaya T, Pirrotta V, et al. Loss of insulator activity by paired $\mathrm{Su}(\mathrm{Hw})$ chromatin insulators. Science. 2001;291(5503):495-8 https://doi.org/10.1126/science.291.5503.495.

88. Cai HN, Shen P. Effects of cis arrangement of chromatin insulators on enhancer-blocking activity. Science. 2001;291(5503):493-5 https://doi.org/1 0.1126/science.291.5503.493.

89. Kyrchanova O, Chetverina D, Maksimenko O, Kullyev A, Georgiev P. Orientation-dependent interaction between Drosophila insulators is a property of this class of regulatory elements. Nucleic Acids Res. 2008;36(22): 7019-28 https://doi.org/10.1093/nar/gkn781.

90. Bartkuhn M, Straub T, Herold M, Herrmann M, Rathke C, Saumweber H, et al. Active promoters and insulators are marked by the centrosomal protein 190. EMBO J. 2009;28(7):877-88 https://doi.org/10.1038/emboj.2009.34.

91. Boyle AP, Davis S, Shulha HP, Meltzer P, Margulies EH, Weng Z, et al. Highresolution mapping and characterization of open chromatin across the genome. Cell. 2008;132(2):311-22 https://doi.org/10.1016/j.cell.2007.12.014.

92. Vorobyeva NE, Mazina MU, Golovnin AK, Kopytova DV, Gurskiy DY, Nabirochkina EN, et al. Insulator protein Su(Hw) recruits SAGA and Brahma complexes and constitutes part of Origin Recognition Complex-binding sites in the Drosophila genome. Nucleic Acids Res. 2013;41(11):5717-30 https://doi.org/10.1093/nar/gkt297.

93. Bohla D, Herold M, Panzer I, Buxa MK, Ali T, Demmers J, et al. A functional insulator screen identifies NURF and dREAM components to be required for enhancer-blocking. PLoS One. 2014;9(9):e107765 https://doi.org/10.1371/ journal.pone.0107765. 
94. Rhee DY, Cho DY, Zhai B, Slattery M, Ma L, Mintseris J, et al. Transcription factor networks in Drosophila melanogaster. Cell Rep. 2014;8(6):2031-43 https://doi.org/10.1016/j.celrep.2014.08.038.

95. Pokholkova GV, Demakov SA, Andreenkov OV, Andreenkova NG, Volkova El, Belyaeva ES, et al. Tethering of CHROMATOR and dCTCF proteins results in decompaction of condensed bands in the Drosophila melanogaster polytene chromosomes but does not affect their transcription and replication timing. PLoS One. 2018;13(4):e0192634 https://doi.org/10.1371/ journal.pone.0192634.

96. Chetverina D, Savitskaya E, Maksimenko O, Melnikova L, Zaytseva O, Parshikov A, et al. Red flag on the white reporter: a versatile insulator abuts the white gene in Drosophila and is omnipresent in mini-white constructs. Nucleic Acids Res. 2008;36(3):929-37 https://doi.org/10.1093/nar/gkm992.

97. Erokhin M, Parshikov A, Georgiev P, Chetverina D. E(y)2/Sus1 is required for blocking PRE silencing by the Wari insulator in Drosophila melanogaster. Chromosoma. 2010;1 19(3):243-53 https://doi.org/10.1007/s00412-009-0253-1.

98. Erokhin M, Davydova A, Kyrchanova O, Parshikov A, Georgiev P, Chetverina D. Insulators form gene loops by interacting with promoters in Drosophila. Development. 2011;138(18):4097-106 https://doi.org/10.1242/dev.062836.

99. Mazina MY, Kovalenko EV, Derevyanko PK, Nikolenko JV, Krasnov AN, Vorobyeva NE. One signal stimulates different transcriptional activation mechanisms. Biochim Biophys Acta Gene Regul Mech. 2018;1861(2):178-89 https://doi.org/10.1016/j.bbagrm.2018.01.016.

\section{Publisher's Note}

Springer Nature remains neutral with regard to jurisdictional claims in published maps and institutional affiliations.

Ready to submit your research? Choose BMC and benefit from:

- fast, convenient online submission

- thorough peer review by experienced researchers in your field

- rapid publication on acceptance

- support for research data, including large and complex data types

- gold Open Access which fosters wider collaboration and increased citations

- maximum visibility for your research: over $100 \mathrm{M}$ website views per year

At $\mathrm{BMC}$, research is always in progress.

Learn more biomedcentral.com/submissions 